\title{
Structure Property Relationships in the Lead-free Piezoceramic System K0.5Bi0.5TiO3 - BiMg0.5Ti0.5O3
}

DOI:

10.1016/j.actamat.2019.02.011

\section{Document Version}

Accepted author manuscript

Link to publication record in Manchester Research Explorer

\section{Citation for published version (APA):}

Hall, D., Li, Y., Milne, S., \& Zeb, A. (2019). Structure Property Relationships in the Lead-free Piezoceramic System K0.5Bi0.5TiO3 - BiMg0.5Ti0.5O3. Acta Materialia, [10.1016/j.actamat.2019.02.011].

https://doi.org/10.1016/j.actamat.2019.02.011

\section{Published in:}

Acta Materialia

\section{Citing this paper}

Please note that where the full-text provided on Manchester Research Explorer is the Author Accepted Manuscript or Proof version this may differ from the final Published version. If citing, it is advised that you check and use the publisher's definitive version.

\section{General rights}

Copyright and moral rights for the publications made accessible in the Research Explorer are retained by the authors and/or other copyright owners and it is a condition of accessing publications that users recognise and abide by the legal requirements associated with these rights.

\section{Takedown policy}

If you believe that this document breaches copyright please refer to the University of Manchester's Takedown Procedures [http://man.ac.uk/04Y6Bo] or contact uml.scholarlycommunications@manchester.ac.uk providing relevant details, so we can investigate your claim.

\section{OPEN ACCESS}




\section{Accepted Manuscript}

Structure-Property Relationships in the Lead-free Piezoceramic System

$\mathrm{K}_{0.5} \mathrm{Bi}_{0.5} \mathrm{TiO}_{3}-\mathrm{BiMg}_{0.5} \mathrm{Ti}_{0.5} \mathrm{O}_{3}$

Aurang Zeb, David A. Hall, Zabeada Aslam, Jennifer Forrester, Jing-Feng Li, Yizhe L. Li, Chiu C. Tang, Ge Wang, Fangyuan Zhu, Steven J. Milne

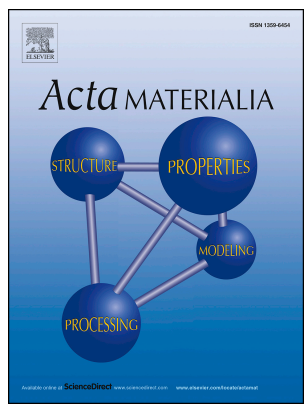

PII:

$$
\text { S1359-6454(19)30089-8 }
$$

DOI: $\quad$ https://doi.org/10.1016/j.actamat.2019.02.011

Reference: $\quad$ AM 15134

To appear in: Acta Materialia

Received Date: 28 November 2018

Revised Date: 6 February 2019

Accepted Date: 7 February 2019

Please cite this article as: A. Zeb, D.A. Hall, Z. Aslam, J. Forrester, J.-F. Li, Y.L. Li, C.C. Tang, G. Wang, F. Zhu, S.J. Milne, Structure-Property Relationships in the Lead-free Piezoceramic System $\mathrm{K}_{0.5} \mathrm{Bi}_{0.5} \mathrm{TiO}_{3}-\mathrm{BiMg}_{0.5} \mathrm{Ti}_{0.5} \mathrm{O}_{3}$, Acta Materialia, https://doi.org/10.1016/j.actamat.2019.02.011.

This is a PDF file of an unedited manuscript that has been accepted for publication. As a service to our customers we are providing this early version of the manuscript. The manuscript will undergo copyediting, typesetting, and review of the resulting proof before it is published in its final form. Please note that during the production process errors may be discovered which could affect the content, and all legal disclaimers that apply to the journal pertain. 


\title{
Aurang Zeb ${ }^{1,2}$, David A. Hall ${ }^{3}$, Zabeada Aslam ${ }^{3}$, Jennifer Forrester ${ }^{1}$, Jing-Feng Li ${ }^{4}$, Yizhe L. Li ${ }^{3}$, Chiu C. Tang $^{5}$, Ge Wang ${ }^{3}$, Fangyuan Zhu ${ }^{6}$, Steven J. Milne ${ }^{1 *}$
}

${ }^{1 .}$ School of Chemical and Process Engineering, University of Leeds, Leeds, LS2 9JT, United Kingdom.

${ }^{2}$ Department of Physics, Islamia College Peshawar, KP, Pakistan.

${ }^{3}$ School of Materials, University of Manchester, Manchester, M13 9PL, United Kingdom.

${ }^{4}$ State Key Laboratory of New Ceramics and Fine Processing, School of Materials Science and Engineering, Tsinghua University, Beijing 100084, China.

${ }^{5}$ Diamond Light Source Ltd, Harwell Science and Innovation Campus, Didcot, Oxfordshire, OX11 0DE, United Kingdom.

${ }^{6}$ Shanghai Institute of Applied Physics, Chinese Academy of Science, Shanghai, 201204, China.

* Corresponding Author: s.j.milne@leeds.ac.uk

\begin{abstract}
Distinctive structure-property relationships are revealed in the relaxor ferroelectric ceramic solid solution, (1$\mathrm{x}) \mathrm{K}_{0.5} \mathrm{Bi}_{0.5} \mathrm{TiO}_{3}-\mathrm{xBiMg}_{0.5} \mathrm{Ti}_{0.5} \mathrm{O}_{3}: 0.02<\mathrm{x}<0.08$. The constructed phase diagram and results of in-situ synchrotron X-ray diffraction provide explanations for temperature and electric field dependent anomalies in dielectric, ferroelectric and electromechanical properties. At room temperature a mixed phase tetragonal and pseudocubic phase field occurs for compositions $0>\mathrm{x} \leq 0.07$. As temperature rises to $\geq$ $150{ }^{\circ} \mathrm{C}$, the ferroelectric tetragonal relaxor phase changes to a pseudocubic ergodic relaxor phase; this change in length scale of polar order is responsible for an inflection in relative permittivity - temperature plots. The transition is reversed by a sufficient electric field, thereby explaining the constricted form of polarisation-electric field loops measured at $>150^{\circ} \mathrm{C}$. It is also responsible for a change in slope of the strain-electric field (S-E) plots which are relatively linear in the ferroelectric regime i.e. at temperatures up to $150{ }^{\circ} \mathrm{C}$, giving unipolar strains of $0.11 \%$ at $20^{\circ} \mathrm{C}$ and $0.14 \%$ at $150{ }^{\circ} \mathrm{C}\left(50 \mathrm{kV} \mathrm{cm}^{-1}\right.$ field $)$. The additional contribution from the effect of the field-induced pseudocubic to tetragonal transition, generates strains of $\sim 0.2 \%$ at $185^{\circ} \mathrm{C}$. Unusual for a piezoelectric solid solution, the maximum strains and charge coefficients $\left(\mathrm{d}_{33}=150 \mathrm{pC} \mathrm{N} \mathrm{N}^{-1}, 20{ }^{\circ} \mathrm{C}\right)$ do not coincide with a morphotropic or polymorphic phase boundary.
\end{abstract}




\section{Introduction}

Lead zirconate titanate (PZT) based ceramics are used in a wide range of sensor, actuator and transducer applications. ${ }^{1}$ Environmental and health concerns surrounding the use of lead oxide have resulted in a search for lead-free alternatives. PZT is a solid solution between $\mathrm{PbZrO}_{3}$ and $\mathrm{PbTiO}_{3}$ in which a phase boundary exists between two ferroelectric phases, rhombohedral and tetragonal (possibly with a bridging monoclinic region). ${ }^{1,2}$ This phase boundary is almost vertical on the $\mathrm{PbZrO}_{3}-\mathrm{PbTiO}_{3}$ phase diagram, and for this reason it is referred to as a morphotropic phase boundary (MPB), only showing significant curvature as temperature approaches the Curie point $\left(T_{\mathrm{c}} \sim 370^{\circ} \mathrm{C}\right)$. The coexistence of ferroelectric phases with differing symmetry and polar directions gives enhanced piezoelectric properties at the MPB due to ease of polarisation rotation. The temperature-insensitive nature of the MPB confers favourable temperature stability to the piezoelectric properties of PZT. ${ }^{1}$ Despite its relatively high $T_{\mathrm{c}}$ the maximum working temperature of most types of PZT is $\sim 200-250{ }^{\circ} \mathrm{C}$, presumably due to a combination of property degradation and instability under electrical and mechanical loading. ${ }^{3,4}$ A range of chemical dopants, commonly classified as donors (soft PZT) or acceptors (hard PZT), are used to tailor the properties of PZT for specific applications.

Numerous lead-free piezoelectrics have been proposed. ${ }^{5}$ In some cases, such as in some early reports of $\mathrm{Na}_{0.5} \mathrm{~K}_{0.5} \mathrm{NbO}_{3}(\mathrm{NKN})$ based systems, a relatively high value of piezoelectric coefficient $\left(d_{33}\right)$ occurs because of phase co-existence at a polymorphic phase transition (PPT) between orthorhombic and tetragonal ferroelectric phases. The PPT is temperature- and composition-dependent and appears as an inclined boundary on the phase diagram, rather than the desired temperature-invariant near-vertical MPB. ${ }^{6-8}$ For various NKN solid solutions, for example $\mathrm{NKN}-\mathrm{LiTaO}_{3}$, a reasonably high value of $\mathrm{d}_{33}$ at room-temperature occurs in compositions for which the PPT occurs at room-temperature however properties degrade significantly as temperature changes. Many piezoelectric devices require stability in properties over a wide temperature range and this has prompted research into devising NKN-type solid solutions in which PPT temperatures are shifted to below room-temperature, as in $\mathrm{NKN}-7 \% \mathrm{LiTaO}_{3}$. This approach has been demonstrated to give stable properties over repeated thermal cycling. ${ }^{7,11}$ Other workers have incorporated substituents that broaden the temperature range of the PPT, which still occurs within the anticipated working temperature range of the piezoelectric. The diffuse nature of the phase transition minimises the variability in measured properties, at least over a single heating cycle. ${ }^{8-10}$

Another promising group of lead-free piezoelectrics are based on $\mathrm{Na}_{0.5} \mathrm{Bi}_{0.5} \mathrm{TiO}_{3}$ (NBT), a relaxor ferroelectric. The coherence length scales of polar order in a relaxor are much shorter than those in a 
conventional ferroelectric, on the nanoscale rather than microscale. The nano-polar structure is generally thought to be due to compositional disorder in the perovskite lattice which prevents long-range ferroelectric domains forming on cooling from the paraelectric state, i.e. from temperatures above the Burns temperature, $T_{\mathrm{B}}$. Chemical variability on the lattice-scale creates fluctuating electrostatic and strain fields that inhibit long range order of the dipoles that originate from off-centre A- and B-site ions within $\mathrm{AO}_{12}$ and $\mathrm{BO}_{6}$ polyhedra respectively. Below $T_{\mathrm{B}}$, the rise in relative permittivity is consistent with an increase in polar order within nanoscale domains and increases in domain size as temperature falls. Eventually, on cooling the dynamics of field-induced dipole reorientation slow down, causing bulk polarization to decrease and creating a broad, frequency-dependent dielectric peak (at temperature $T_{\mathrm{m}}$ ). On further cooling, a change from ergodic to non-ergodic relaxor (ferroelectric) behaviour occurs as the dipoles 'freeze'.

Lead-free piezoelectrics based on relaxor ferroelectrics such as NBT generally exhibit improved temperature stability of properties compared to many NKN-based counterparts. Binary solid solutions of NBT with $\mathrm{BaTiO}_{3}(\mathrm{BT})$ or $\mathrm{K}_{0.5} \mathrm{Bi}_{0.5} \mathrm{TiO}_{3}(\mathrm{KBT})$ display an MPB, and for this reason NBT-BT and NBTKBT systems have attracted great interest. ${ }^{13-18}$ Their $d_{33}$ values are in the range $122-176 \mathrm{pC} / \mathrm{N}$ for MPB NBT-BT compositions, ${ }^{5}$ and $140-190 \mathrm{pC} / \mathrm{N}$ for NBT-KBT. ${ }^{5,19-21}$ Strains of up to $0.4 \%$ in NBT-BT arise from a reversible field induced phase transition. ${ }^{22}$ However modest depolarisation temperatures $\left(T_{\mathrm{d}}\right)$ for compositions with the best piezoelectric properties pose a significant drawback. Ceramics of NBT-BT near the MPB have $T_{\mathrm{d}}$ values of $90-120^{\circ} \mathrm{C} .{ }^{5,23}$ Corresponding $T_{\mathrm{d}}$ values are slightly higher for NBT-BKT, at $130-170^{\circ} \mathrm{C}^{5}$

Ternary NBT based systems include NBT-KBT-BT, ${ }^{24,25}$ typically with $d_{33} \sim 170 \mathrm{pC} / \mathrm{N}$ and $T_{\mathrm{d}} \sim$ $162^{\circ} \mathrm{C}$, and NBT-BT-NKN which develops 'giant' electromechanical bipolar strains up to $\sim 0.45 \%$ in the MPB region due to a reversible electric field-induced phase transformation at high drive fields, as does NBT-KBT-NKN. ${ }^{26-28}$ The field-induced transformation gives rise to a characteristic discontinuity in S-E plots and increased strain hysteresis. For actuator applications, narrow S-E loops with low hysteresis are preferred in order to provide improved positional accuracy and to minimize self-heating problems and possible depolarisation.

There is limited literature on KBT-based piezoelectrics. ${ }^{29-33}$ Although unmodified KBT exhibits relatively low field-induced strain values, it has attracted interest because of its high depolarisation temperature, $T_{\mathrm{d}} \sim 250{ }^{\circ} \mathrm{C}$. Many electromechanical device applications involve high operating temperatures, for example $150{ }^{\circ} \mathrm{C}$ for fuel injection systems. ${ }^{29,30}$ However, costly hot pressing is required to fabricate high density KBT and to achieve suitable levels of strain, for example a strain of $0.04 \%$ is reported for conventionally fabricated ceramics and $\sim 0.12 \%$ for hot pressed KBT (at $80 \mathrm{kV} / \mathrm{cm}$ ). ${ }^{29,30} \mathrm{By}$ modifying $\mathrm{KBT}$ with $\mathrm{Bi}\left(\mathrm{Mg}_{0.5} \mathrm{Ti}_{0.5}\right) \mathrm{O}_{3}$ (BMT), it was shown that improved values of $d_{33}$ and room- 
temperature electromechanical bipolar strains could be obtained for conventionally processed ceramics.

31,32 This article reports structure-property relationships in KBT-BMT ceramics and reveals reasons for the temperature- and field-dependent discontinuities in properties. Unusually for a piezoelectric solid solution, electromechanical property enhancements are not correlated with a phase boundary, instead maximum charge coefficients and field induced strains occur within a two phase tetragonal and pseudocubic region at approximately a 50/50 ratio of the two phases.

\section{Experimental Procedures}

Sample compositions were prepared, using conventional solid state processing, according to the formula (1-x) $\mathrm{K}_{0.5} \mathrm{Bi}_{0.5} \mathrm{TiO}_{3}-\mathrm{xBi}\left(\mathrm{Mg}_{0.5} \mathrm{Ti}_{0.5}\right) \mathrm{O}_{3}$ [KBMT] for the compositional range $0 \leq \mathrm{x} \leq 0.12$. The assumed solid solution formula is: $\mathrm{K}_{(0.5-0.5 \mathrm{x})} \mathrm{Bi}_{(0.5+0.5 \mathrm{x})} \mathrm{Ti}_{(1-0.5 \mathrm{x})} \mathrm{Mg}_{(0.5 \mathrm{x})} \mathrm{O}_{3}$, with $\mathrm{K}^{+}$and $\mathrm{Bi}^{3+}$ on A-sites and $\mathrm{Ti}^{4+}$ and $\mathrm{Mg}^{2+}$ occupying B- sites of the perovskite lattice. The reagents were $\mathrm{K}_{2} \mathrm{CO}_{3}$ (Sigma Aldrich, $99 \%$ purity), $\mathrm{Bi}_{2} \mathrm{O}_{3}$ (Sigma Aldrich, 99.9\%), $\mathrm{MgO}$ (Alfa Aesar, 99.9\%) and $\mathrm{TiO}_{2}$ (Sigma Aldrich, 99.9\%). After drying overnight at $250{ }^{\circ} \mathrm{C}$ and cooling to room-temperature, the powders were stored in a desiccator under reduced pressure and subsequently weighed in the appropriate ratios. The powders were then ball milled with $\mathrm{ZrO}_{2}$ grinding media in isopropanol for $24 \mathrm{~h}$; the dried slurries were passed through a $300 \mu \mathrm{m}$ mesh nylon sieve and calcined at $850^{\circ} \mathrm{C}$ for $3 \mathrm{~h}$ in alumina crucibles with heating and cooling ramp rates of $300{ }^{\circ} \mathrm{C} / \mathrm{h}$. After calcination, the sieved powders were milled again for $24 \mathrm{~h}$ and $1 \mathrm{wt} \%$ binder was added (Ciba Glascol HA4: Ciba Speciality Chemicals, Bradford, UK). Pellets of $10 \mathrm{~mm}$ diameter and $\sim 1.5 \mathrm{~mm}$ thickness were pressed uniaxially at $100 \mathrm{MPa}$ in a steel die, followed by cold isostatic pressing at $200 \mathrm{MPa}$. The binder was burned out by heating at $50{ }^{\circ} \mathrm{C} / \mathrm{h}$ to $550{ }^{\circ} \mathrm{C}$, followed by heating at $300{ }^{\circ} \mathrm{C} / \mathrm{h}$ to sintering temperatures of $1050{ }^{\circ} \mathrm{C}$ to $1100{ }^{\circ} \mathrm{C}$ with a $4 \mathrm{~h}$ dwell period. There was a narrow range of temperatures in which densification could be obtained, above which partial melting occurred. Pellets were embedded in a powder of the same composition during sintering to minimise losses due to volatilisation of $\mathrm{K}_{2} \mathrm{O}$ and $\mathrm{Bi}_{2} \mathrm{O}_{3}$.

High-resolution synchrotron X-ray powder diffraction (SXPD) measurements at room-temperature were performed on beamline $\mathrm{I} 11^{34}$ at the Diamond Light Source, UK. Powder samples were prepared by crushing and grinding the as-sintered ceramic pellets, followed by loading into glass capillaries with a diameter of $0.3 \mathrm{~mm}$. SXPD patterns were obtained using a photon energy of $15 \mathrm{keV}$, corresponding to a wavelength of $0.825838(10) \AA$, and the resulting diffraction patterns were recorded using multi-analyser crystal (MAC) detectors at room-temperature. Calibrated was performed using a high quality Si powder standard, and the step-size was $0.001^{\circ} 2 \theta$. Full-pattern refinement was carried out using the Rietveld analysis program GSAS. ${ }^{35}$ 
High temperature X-ray diffraction (XRD) patterns were recorded using laboratory XRD, with $\mathrm{CuK}_{\alpha}$ radiation $\lambda=1.54056 \AA$, and a scan speed $1 \%$ min over the temperature range from $25{ }^{\circ} \mathrm{C}$ to $400{ }^{\circ} \mathrm{C}$ using a PANalytical X'Pert Pro MPD diffractometer (Philips, Almelo, Netherlands) fitted with a HTK 1200 oven and TCU 1000 controller (Paar Physica): peak profile fitting was performed using the X'Pert Highscore Plus software.

In-situ sychrotron XRD experiments were carried out in transmission on beamline I15 of the Diamond Light Source, using a high energy monochromatic x-ray beam having a photon energy of $76 \mathrm{keV}(\lambda=0.16314 \AA)$ and a cross-section of approximately $70 \mu \mathrm{m}$. Test specimens were prepared in the form of square-ended beams having dimensions $\sim 1 \mathrm{~mm}$ x $1 \mathrm{~mm}$ x $5 \mathrm{~mm}$, by diamond machining. 2-D XRD images were recorded using a Perkin-Elmer XRD1621 flat-panel detector, with a collection time of 10 s. Subsequently, the detector was calibrated with $\mathrm{LaB}_{6}$ standard powder and 1-D diffraction patterns corresponding to a range of azimuthal angles, $\psi$, were obtained using DAWN ${ }^{42}$. A Matsusada ECA-10 high voltage amplifier was employed to apply an electric field between the upper and lower faces of the test specimen, perpendicular to the X-ray beam, with the sample being immersed in silicone oil to avoid electrical arcing.

For electrical measurements, the sintered pellets were ground to $\sim 1 \mathrm{~mm}$ thickness and silver paste (Agar Scientific) was applied to opposite parallel faces; the pellets were heated in a furnace at $550{ }^{\circ} \mathrm{C}$ for $10 \mathrm{~min}$ to form electrodes. Relative permittivity and loss tangent were recorded as a function of temperature using an impedance analyser (HP Agilent, 4192A Hewlett Packard, Santa Clara, CA), from $25^{\circ} \mathrm{C}$ to $600^{\circ} \mathrm{C}$. For piezoelectric testing, samples were poled in silicone oil by applying a dc field of 40 $60 \mathrm{kV} / \mathrm{cm}$ at a temperature of $\sim 80^{\circ} \mathrm{C}$ for $20 \mathrm{~min}$. The piezoelectric charge coefficients, $d_{33}$, were measured $24 \mathrm{~h}$ after poling, using the Berlincourt technique (Piezotest meter PM 300; Piezotest, London, UK). Strain-electric field and polarization-electric field data were obtained using a ferroelectric analyzer (aixACCT TE1000, aixACCT Systems GMbH, Aachen, Germany) at various temperatures, with a frequency of $1 \mathrm{~Hz}$. The equipment used to measure high-temperature strains permitted a maximum drive field of $50 \mathrm{kV} / \mathrm{cm}$. Electrical resistivity, $\rho$, was measured using a Kiethley Electrometer: $\rho_{300} \mathrm{c}$ was $\sim 2 \mathrm{x}$ $10^{9} \Omega \mathrm{m}$.

High temperature ferroelectric hysteresis measurements were carried out in a silicone oil bath over the temperature range from $25-175^{\circ} \mathrm{C}$ using a HP33120A function generator in combination with a HVA1B high voltage $( \pm 5 \mathrm{kV})$ amplifier (Chevin Research, Otley, UK). The measured electric field-time and current-time waveforms were processed to yield near-saturated polarization-electric field (P-E) loops in the high (super-coercive) field region and effective dielectric properties $\left(\varepsilon_{\mathrm{r}}^{\prime}, \varepsilon_{\mathrm{r}}^{\prime \prime}, \tan \delta\right.$ ) in the medium (sub-coercive) field region using the method described previously. ${ }^{38-40}$ Scanning electron microscopy 
(SEM) was carried out using a Hitachi SU 8230 FESEM. Transmission electron microscopy (TEM) was performed using an FEI Tecnai field emission gun (FEG)-transmission electron microscope operating at $200 \mathrm{kV}$ and fitted with an Oxford Instruments $80 \mathrm{~mm}$ X-Max SDD energy dispersive X-ray (EDX) spectrometer and a Gatan Orius SC600A CCD camera; non-ambient TEM was carried out with a hotstage sample holder using the same instrument.

\section{Results and Discussion}

\subsection{Phase Analysis}

Full-pattern refinement of high resolution synchrotron X-ray powder diffraction (SXPD) data on crushed sintered pellets at room-temperature confirm the KBT end-member to be single phase tetragonal, $P 4 \mathrm{~mm}$. Modification with $x=0.02 \mathrm{BMT}$ (the lowest BMT content studied) generates a mixed tetragonal and cubic $P m \overline{3} m$ phase, as indicated by the fitted parameters listed in Table 1. The mixed phase region extends to $x \leq 0.07$, with a rising proportion of cubic phase with increasing $x$ (Table 1). Composition $x=$ 0.08 is single phase cubic, while $x=0.1$ and 0.12 are cubic with minor amounts of $\mathrm{Bi}_{4} \mathrm{Ti}_{3} \mathrm{O}_{12}$ present. 
Table 1. Summary of crystallographic parameters and phase fractions determined from full pattern refinement of high resolution SXPD data.

\begin{tabular}{|l|c|c|c|c|c|c|c|}
\hline Composition & $\begin{array}{c}\text { Lattice } \\
\text { parameter } a \\
\text { (Tetragonal) }\end{array}$ & $\begin{array}{c}\text { Lattice } \\
\text { parameter } c \\
\text { (Tetragonal) }\end{array}$ & $\begin{array}{c}c / a \\
\text { ratio }\end{array}$ & $\begin{array}{c}\text { Lattice } \\
\text { parameter } \\
\text { (Cubic })\end{array}$ & $\begin{array}{c}\text { Phase fraction } \\
\%\end{array}$ & $\begin{array}{c}w R_{\mathrm{p}} \\
\%\end{array}$ & $\begin{array}{c}R_{\mathrm{p}} \\
\%\end{array}$ \\
& $\AA$ & $\AA$ & $\AA$ & & \\
KBT & $3.92365(4)$ & $4.00746(5)$ & $1.02136(3)$ & - & $100 \% \mathrm{~T}$ & 9.34 & 7.36 \\
0.98KBT-0.02BMT & $3.92493(5)$ & $4.00169(2)$ & $1.01956(4)$ & $3.94640(3)$ & $59.1(2) \mathrm{T} / 40.9(2) \mathrm{C}$ & 8.63 & 6.42 \\
0.97KBT-0.03BMT & $3.92597(4)$ & $3.99814(2)$ & $1.01838(4)$ & $3.94739(3)$ & $52.4(2) \mathrm{T} / 47.6(2) \mathrm{C}$ & 7.76 & 5.58 \\
0.96KBT-0.04BMT & $3.92777(6)$ & $3.99553(1)$ & $1.01719(4)$ & $3.94839(4)$ & $42.8(2) \mathrm{T} / 57.2(2) \mathrm{C}$ & 7.73 & 5.80 \\
0.93KBT-0.07BMT & $3.93707(2)$ & $3.98470(3)$ & $1.01210(2)$ & $3.95061(2)$ & $25.5(2) \mathrm{T} / 74.5(2) \mathrm{C}$ & 7.69 & 5.75 \\
\hline
\end{tabular}

A full pattern Rietveld refinement of the $x=0.03$ composition, which displays the best electromechanical properties, is shown in Figure 1a, along with detail of the $\{110\},\{111\}$ and $\{200\}$ diffraction profiles, Figure 1b. Refinement parameters for the various KBMT compositions are shown in Table S1, Supporting Information. The tetragonal lattice parameters showed a slight contraction along the $c$-axis and an expansion of the $a$-axis with increasing BMT content: the tetragonal $c / a$ ratio decreased from 1.02136(3) for KBT $(x=0.00)$ to $1.01838(4)$ at $x=0.03 \mathrm{KBMT}$, Table 1 and Figure S1, Supporting Information. The cubic lattice parameters increased marginally with increasing BMT content, Figure S1. Systematic variations in the lattice parameters of both phases as a function of $\mathrm{x}$ indicate that they each are solid solutions. 


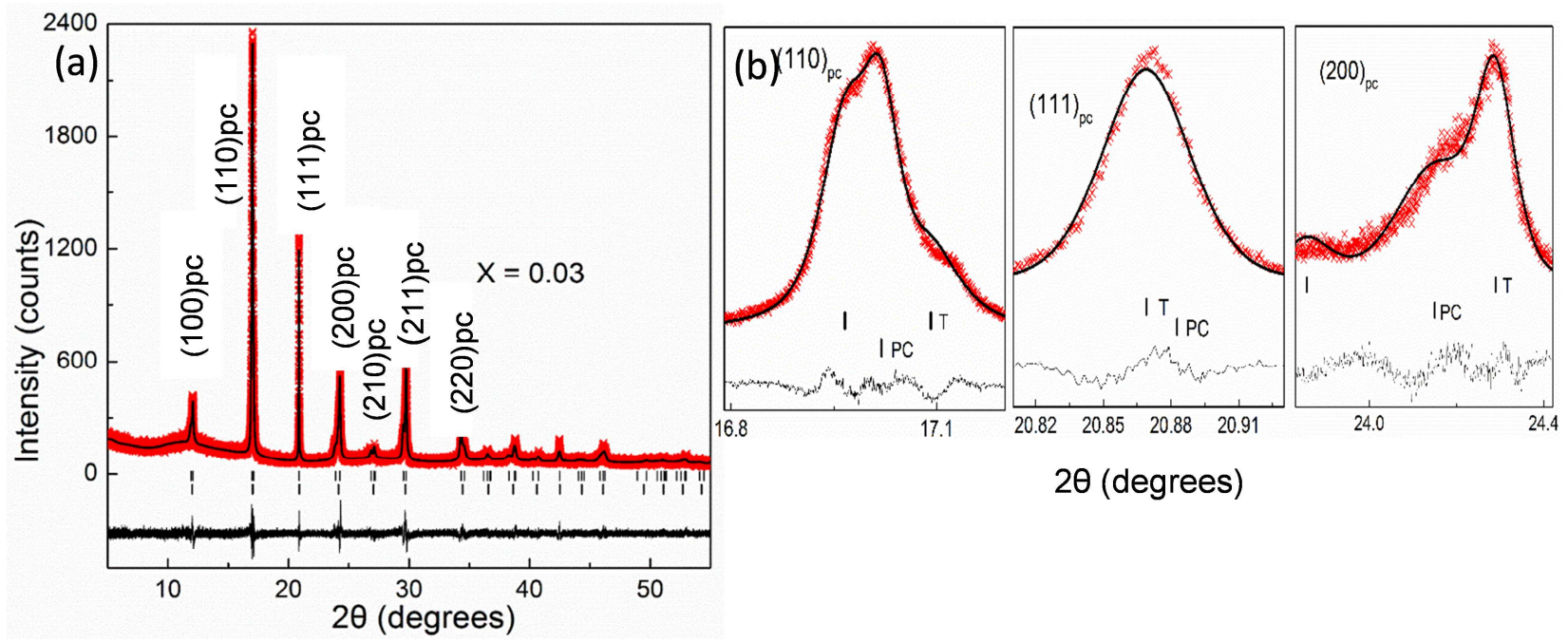

Figure 1. a) SXPD full pattern refinement of $x=0.03$ KBMT, confirming the presence of tetragonal and cubic/pseudocubic phases $\left(h k l_{p}\right), R_{p}=5.58 \%$. b) Expanded view of the $\{110\},\{111)$, and $\{200\}$ diffraction profiles (PC denotes pseudocubic indices).

The phase diagram for KBMT, as determined from SXPD data at $25{ }^{\circ} \mathrm{C}$ combined with laboratory XRD data, recorded over the temperature range $50-400{ }^{\circ} \mathrm{C}$ (at $25{ }^{\circ} \mathrm{C}$ increments), is shown in Figure 2; representative high temperature XRD patterns appear in Figure S2, Supporting Information. The KBT end-member is single phase tetragonal from 25 to $280{ }^{\circ} \mathrm{C}$, becoming mixed tetragonal and cubic between 280 and $310^{\circ} \mathrm{C}$, above which it becomes single phase cubic (' $T_{\mathrm{ST}}$ ' is used hereafter to signify the temperature of the structural transition to single phase cubic). The effect of incorporating BMT is to stabilise the mixed phase region to room-temperature for KBMT solid solution compositions with $0.02 \leq x \leq 0.07$. The $T_{\mathrm{ST}}$ value for $x=0.02$ is similar to that of KBT $(x=0)$, but then decreases with further increases in $x$, the sharpest fall occurring at $x>0.06 ; T_{\mathrm{ST}}$ reaches room-temperature (or below) at $x$ $=0.08$, as shown in Figure 2. Synchrotron XRD reported in Section 3.3 indicate the tetragonal to pseudocubic structural transition occurs at lower temperatures in dense sintered ceramics (Figure 2 relates to powders obtained by crushing sintered pellets). The $c$ and $a$ tetragonal lattice parameters of solid solution compositions converge with increasing temperature in the manner of a typical ferroelectric on approaching its Curie point, Figure S3,Supporting Information. Grain sizes were sub-micron with evidence of non- $180^{\circ}$ domains in some grains, Figure 3, consistent with the tetragonal phase identified by XRD. 


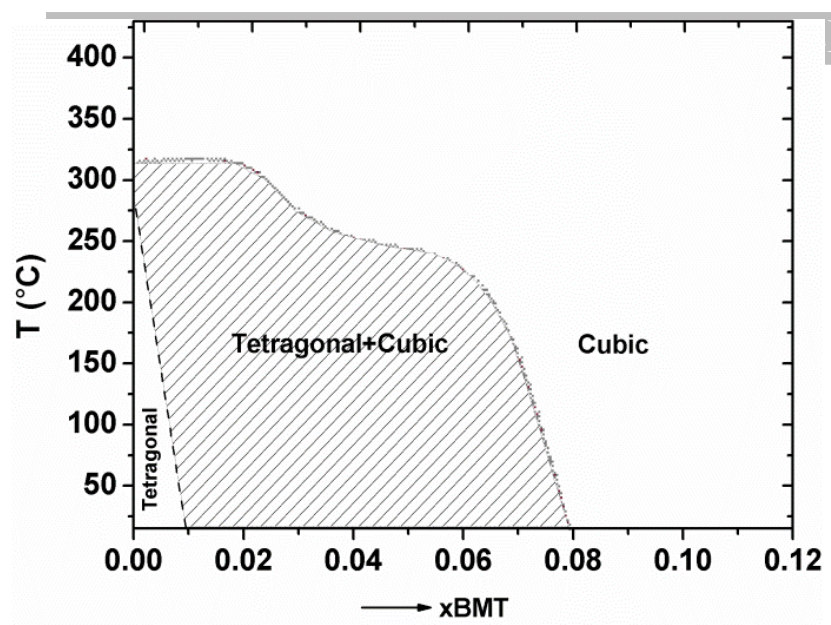

Figure 2. Phase diagram for the KBMT ceramic system based on XRD of crushed sintered pellets. The phase indicated as cubic by XRD is subsequently shown to be pseudocubic (see text).
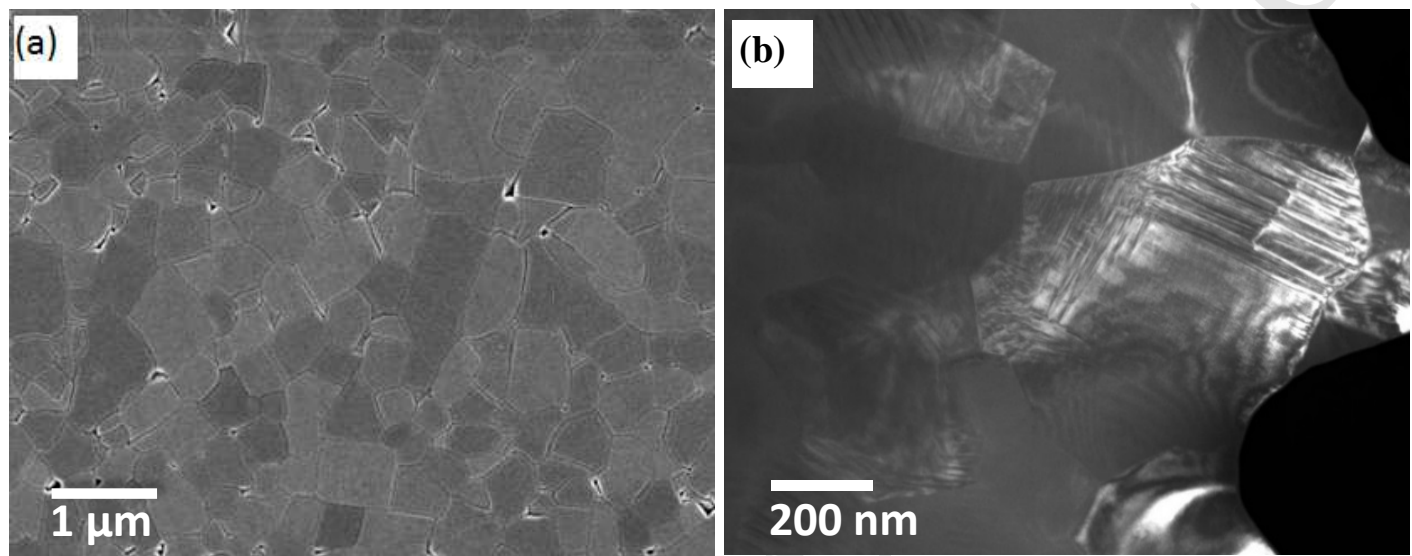

Figure 3. a) SEM micrograph of $x=0.03$ showing the submicron grain size. b) TEM micrograph (unheated sample) showing a tetragonal domain structure in a proportion of the grains. Other nondomain structured grains may be pseudocubic, or tetragonal at differing orientations.

\section{3..2 Dielectric, Ferroelectric and Piezoelectric Properties}

Unpoled KBT shows an inflection in the $\varepsilon_{\mathrm{r}}-\mathrm{T}$ plots well below the peak temperature, $\mathrm{T}_{\mathrm{m}}$. There are reports in the research literature that this type of inflection in a relaxor represents its depolarisation temperature. Alternatively it has been suggested that a changeover from ferroelectric non-ergodic to ergodic state (non-ferroelectric) below the true depolarisation temperature is responsible. The results described below are consistent with the latter interpretation. Unpoled KBMT ceramics show no such inflection $^{31,32}$ but poling was found to induce a weak inflection, starting at $\sim 150-170{ }^{\circ} \mathrm{C}$ (heating cycle), Figure 4. Thus an electric field stimulus is required to generate ferroelectric character in the non-ergodic regime for KBMT but unmodified KBT spontaneously transforms to ferroelectric. The weak nature of 
the inflection in KBMT leads to uncertainty as to its true onset temperature. However the loss tangent plot for $\mathrm{x}=0.03$ shows a more noticeable discontinuity: values begin to rise on the heating cycle at temperatures above $\sim 150^{\circ} \mathrm{C}$ reaching a broad maximum at $\sim 220^{\circ} \mathrm{C}(1 \mathrm{kHz})$; this peak temperature in tan $\delta$ is similar to the depolarisation temperature $T_{\mathrm{d}}$ obtained from charge decay measurements, confirming the $\tan \delta$ data to be a reliable indicator of $\mathrm{T}_{\mathrm{d}} \cdot{ }^{31,32}$ The depolarisation of KBMT occurs at $\sim 220^{\circ} \mathrm{C}$, which is significantly higher than the $\mathrm{T}_{\mathrm{d}}$ of NBT-BT based piezoceramics. ${ }^{5,19-21,36}$.
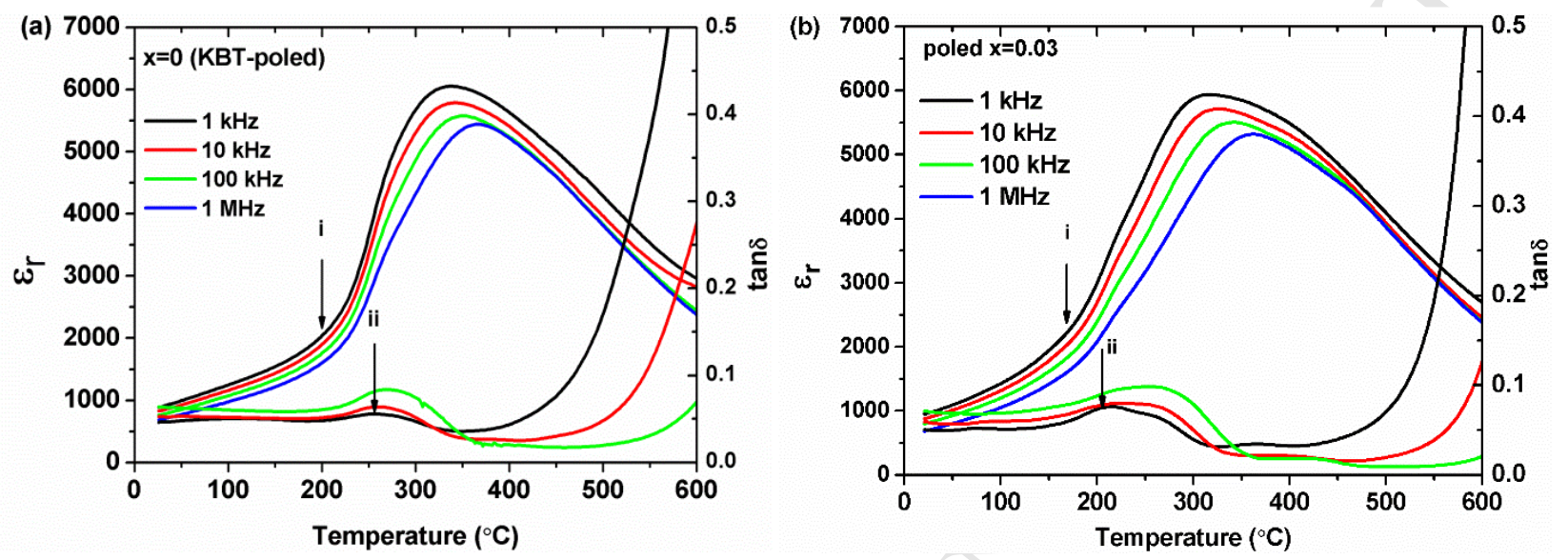

Figure 4. Relative permittivity and loss tangent versus temperature for a) $x=0$ (KBT-poled), b) $x=$ 0.03-poled (arrow indicates the onset temperature of the inflection in (i) $\varepsilon_{\mathrm{r}}$ and (ii) tan $\delta$ due to the changeover from ferroelectric to ergodic relaxor on heating. The peak in $\tan \delta$ at $\sim 220^{\circ} \mathrm{C}$ correlates with the depolarisation temperature. ${ }^{32}$

Polarisation-electric field (P-E) measurements for mixed-phase $x=0.03$ KBMT show broad ferroelectric hysteresis loops at $25{ }^{\circ} \mathrm{C}$, Figure 5. At higher temperatures the loops become narrower, which is consistent with the thermally-induced contraction in cla ratio of the tetragonal phase (Figure S3) and a resultant lowering of the coercive field, $E_{\mathrm{c}}$. Remnant polarisation, $P_{\mathrm{r}}$, values are $\sim 20 \mu \mathrm{C} / \mathrm{cm}^{2}$ at temperatures between $25^{\circ} \mathrm{C}$ and $125^{\circ} \mathrm{C}$, reducing to $\sim 15 \mu \mathrm{C} / \mathrm{cm}^{2}$ at $150{ }^{\circ} \mathrm{C}$. A change in the shape of the P-E loops occurs at $175{ }^{\circ} \mathrm{C}$ due to constriction and partial loss of polarisation at low fields, with $P_{\mathrm{r}}$ reducing to $\sim 10 \mu \mathrm{C} / \mathrm{cm}^{2}$. For the single-phase tetragonal parent $\mathrm{KBT}$ material, no ferroelectric P-E response was observed at temperatures from $25{ }^{\circ} \mathrm{C}$ to $100{ }^{\circ} \mathrm{C}$, indicating that a higher energy is required to initiate domain wall movement than is the case for KBMT, even though the cla ratios are only marginally different (Table 1). 


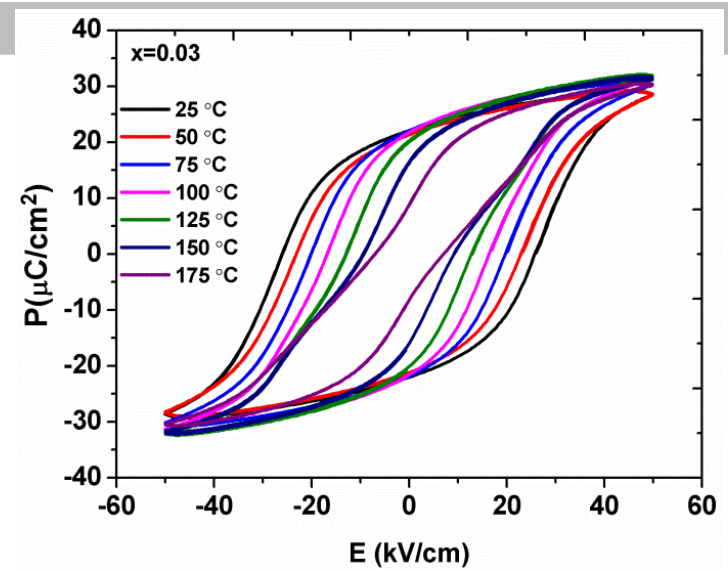

Figure 5. Polarization-electric field loops as a function of temperature for $x=0.03(50 \mathrm{kV} / \mathrm{cm})$ showing partial constriction at $175^{\circ} \mathrm{C}$ due to loss of low-field polarisation resulting from the onset of the change from ferroelectric to ergodic relaxor.

The $x=0.08$ composition, which is single phase cubic according to the SXPD results, exhibits a ferroelectric P-E loop (Figure S4, Supporting Information). This indicates the occurrence of a field induced transition which is confirmed by in situ synchrotron XRD (as described below). Thus it is more accurate to refer to the 'cubic' phase as pseudocubic since its symmetry is field-dependent.

The temperature-dependence of the nonlinear dielectric properties was evaluated by analysis of PE loops obtained from measurements in the sub-coercive field region, from 1 to $20 \mathrm{kV} / \mathrm{cm}$, over a range of temperatures from 25 to $150^{\circ} \mathrm{C}$. The results presented in Figure 6 for $x=0.03 \mathrm{KBMT}$ show that the dielectric permittivity values increase in a linear fashion with increasing field amplitude in accordance with the empirical Rayleigh law, which is typical for many ferroelectrics. ${ }^{38}$ The Rayleigh coefficients, $\alpha$, representing the gradient of the $\varepsilon_{\mathrm{r}}$-T plots, increase with increasing temperature as a result of the increasing extrinsic (domain wall) contribution to permittivity. For example, for $x=0.03$ KBMT, the value of $\alpha^{\prime}$ increases from $0.32 \times 10^{-3}$ to $1.06 \times 10^{-3} \mathrm{~m} / \mathrm{V}$ as the temperature increases from $25^{\circ} \mathrm{C}$ to $150^{\circ} \mathrm{C}$. At room-temperature, these Rayleigh coefficients are significantly lower than those of soft PZT $\left(5.6 \times 10^{-3} \mathrm{~m} / \mathrm{V}\right)$ and are comparable to those of hard PZT $\left(0.67 \times 10^{-3} \mathrm{~m} / \mathrm{V}\right) .^{39,40}$ This result is in accord with the relatively high coercive fields of KBMT ceramics at room-temperature.

The loss tangent values measured from the P-E loops in the sub-coercive field region also increase progressively as a function of increasing field amplitude and temperature, as illustrated in Figure 5. The trends in $\tan \delta$ are similar to those obtained for $\varepsilon_{\mathrm{r}}$. Although the loss tangent values reported here for the KBMT ceramics seem relatively high, it should be noted that these represent the 'high field' values and they are in fact comparable with those of soft PZT ceramics reported by Hall. ${ }^{39,40}$ In general, the nonlinear dielectric properties of the KBMT ceramics in the temperature range from 25 to $150{ }^{\circ} \mathrm{C}$ 
conform to those of a conventional ferroelectric ceramic. Further deviations from this behaviour are anticipated at higher temperatures due to the decay of the long range-ordered ferroelectric state.
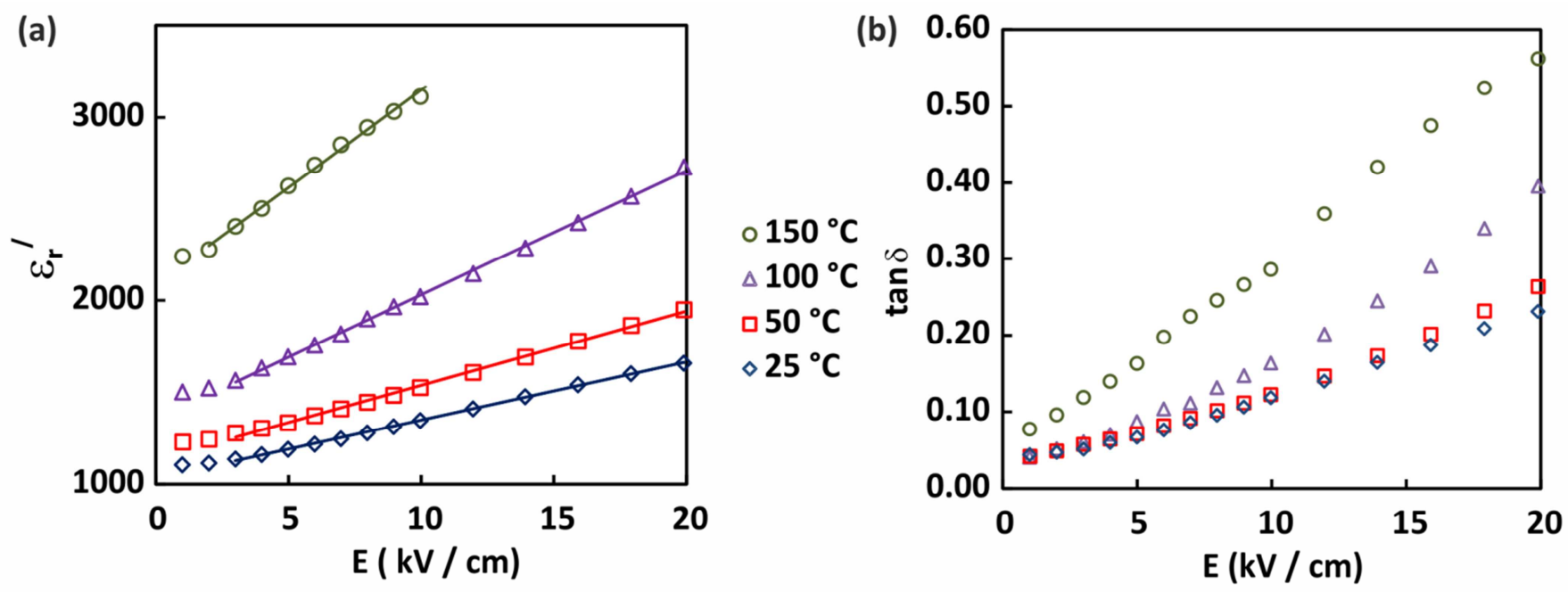

Figure 6. a) Nonlinear dielectric permittivity, and b) loss tangent data for $x=0.03$ ceramics measured over a range of electric field amplitudes and temperatures.

The compositional dependence of the direct piezoelectric coefficient $d_{33}$ (measured by the Berlincourt method) is illustrated in Figure 7. A sharp increase in $d_{33}$ occurs between $x=0.02$ and 0.03 , giving a value of $150 \mathrm{pC} / \mathrm{N}$ for $x=0.03$, then it reduces with further increases in BMT content. The maximum $d_{33}$ values lie within the upper range reported for NBT-BT and NBT-KBT ceramics, ${ }^{5}$ No phase boundary was induced at $x=0.03$ by the application of an electric field, confirming that $\mathrm{d}_{33}(\max )$ is independent of a phase transition. 


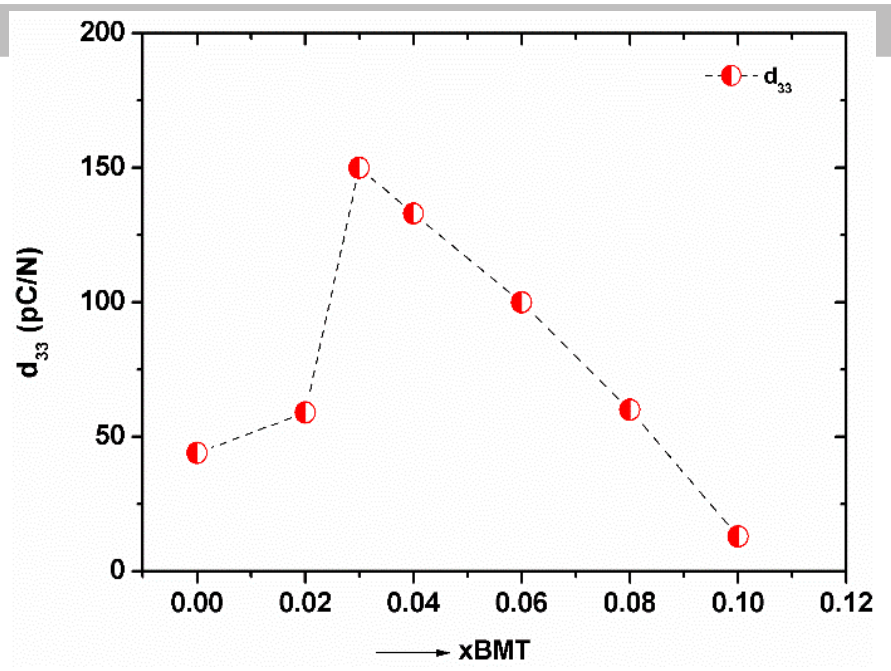

Figure 7. Variation of piezoelectric charge coefficient, $d_{33}$, versus $x$ for the KBMT system.

The $x=0.03$ KBMT sample showed a two-fold increase in electric field-induced strain relative to $x$ $=0 \mathrm{KBT}$, giving a value of $0.11 \%$, which is $\sim 25 \%$ lower than that for a commercial hard PZT $806(50$ $\mathrm{kV} / \mathrm{cm}, 1 \mathrm{~Hz}$ ), as illustrated by the results presented in Figure 8 . Increasing the field level to $80 \mathrm{kV} / \mathrm{cm}$ (at $1 \mathrm{~Hz}$ ) results in a strain of $0.3 \%$ for KBMT; this compares to a 'giant' strain of $0.45 \%$ (at a much lower measurement frequency of $50 \mathrm{mHz}$ ) reported for NBT-BT-NKN ceramics under a comparable field. ${ }^{26}$ For a field amplitude of $20 \mathrm{kV} / \mathrm{cm}$, which is below $E_{\mathrm{c}}$, a strain of $0.06 \%$ was recorded for $x=0.03$ (Figure S6, Supporting Information).

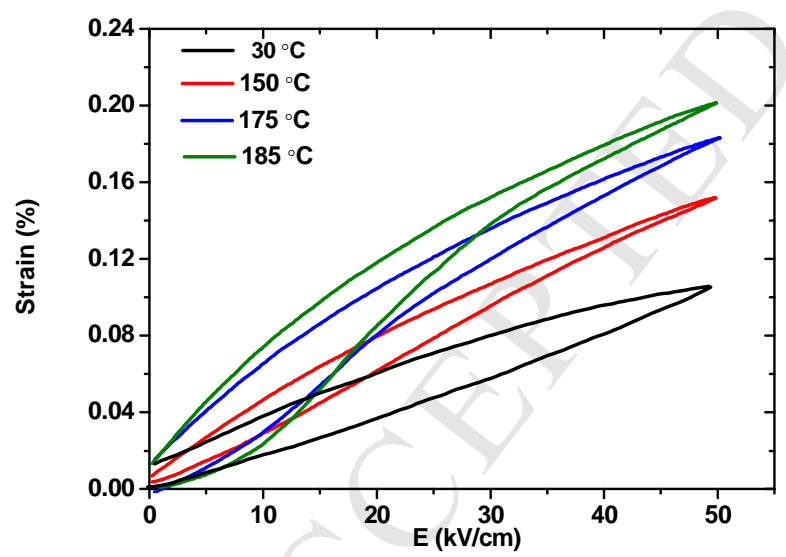

Figure 8. Unipolar S-E loops for $x=0.03$ showing elliptical loops with low hysteresis for temperatures up to $150{ }^{\circ} \mathrm{C}$ followed by a change in shape at $175{ }^{\circ} \mathrm{C}$ and $185{ }^{\circ} \mathrm{C}$ with increased hysteresis (span in $\mathrm{S}$ values). 
With increasing temperature the unipolar field-induced strains of $x=0.03$ increase linearly from $0.11-0.14 \%$, as temperature increases to $150^{\circ} \mathrm{C}$, with low hysteresis in strain values, Figures 8 and 9(a). The relatively low hysteresis (span in S values) and near-linearity in the S-E relationship with increasing temperature up to $150{ }^{\circ} \mathrm{C}$ (Figure S6), are distinctive in the field of $\mathrm{Pb}$-free piezoelectrics. The temperature dependence of the unipolar S-E response equates to a consistent variation in strain of $3 \times 10^{-4}$ $\%$ per ${ }^{\circ} \mathrm{C}$. This linearity represents the behaviour of the ferroelectric non ergodic state; there is no evidence of temperature- or electric field-induced phase transitions between 20 and $150{ }^{\circ} \mathrm{C}$.

At $175^{\circ} \mathrm{C}$ and $185^{\circ} \mathrm{C}$ there is a change in shape of the S-E loops, Figure 8, which translates to a steeper $\mathrm{S}_{\max }-\mathrm{T}$ plot, Figure 9a, with $\mathrm{S}$ reaching $\sim 0.2 \%$ at $185{ }^{\circ} \mathrm{C}$. The S-E loops were relatively narrow and elliptical at $\leq 150{ }^{\circ} \mathrm{C}$ but change at higher temperatures to broader loops (higher hysteresis) and with a discontinuity (bulge) on the up-field cycle, Figure 8. This change in the S-E relationship is attributed to the change to ergodic relaxor characteristics above $150{ }^{\circ} \mathrm{C}$ and a reversible field-induced transformation into the ordered ferroelectric state.

Trends in the effective high-field $d_{33} *\left(\mathrm{~S}_{\max } / \mathrm{E}_{\max }\right)$ values with temperature for $\mathrm{x}=0.03$ are presented in Figure 9b, and the strain-field maximum hysteresis values in Figure 9c. A slight decrease in hysteresis between $120{ }^{\circ} \mathrm{C}$ and $150{ }^{\circ} \mathrm{C}$ is consistent with a reduction in energy barrier of tetragonal domain wall movement due to a lower $E_{\mathrm{c}}$ as the $c / a$ tetragonal distortion decreases. Measured strain hysteresis values are $0.02-0.025 \%$ (absolute) for temperatures up to $150{ }^{\circ} \mathrm{C}$, which compare favourably to other lead-free piezoelectrics. ${ }^{5}$ The occurrence of the field-dependent transition causes $\mathrm{S}_{\max }$ and hysteresis in the S-E relationship to increase at temperatures above $150{ }^{\circ} \mathrm{C}$, giving a hysteresis of $0.035 \%$ at $175^{\circ} \mathrm{C}$ and $\sim 0.05 \%$ at $185{ }^{\circ} \mathrm{C}$. 

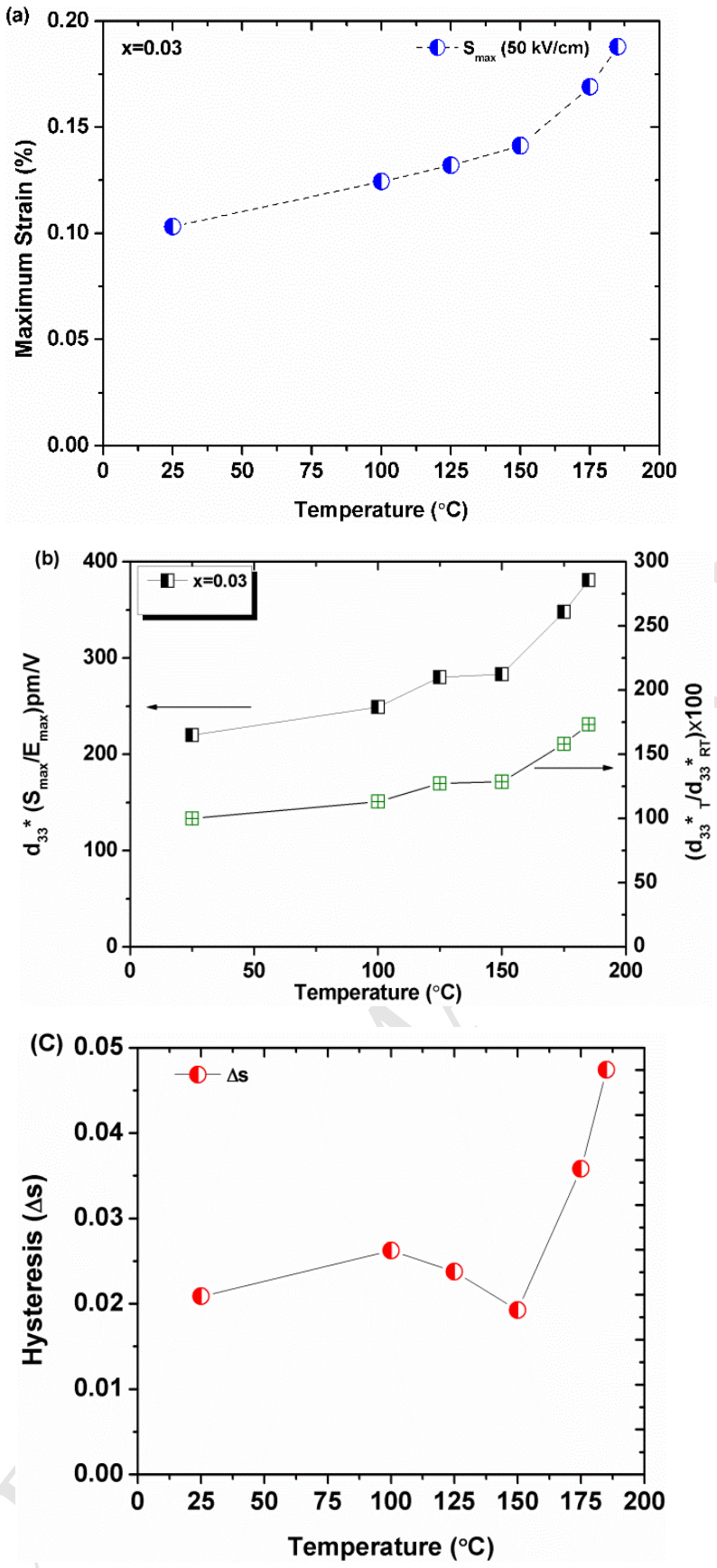

Figure 9. a) Temperature-dependent unipolar strain, $S_{\max }$, at $50 \mathrm{kV} / \mathrm{cm}(1 \mathrm{~Hz})$, b) temperature variation of effective $d_{33} *\left(S_{\max } / E_{\max }\right)$ and normalized values, $d_{33} * T / d_{33}{ }^{*} \mathrm{RT}$ c) strain maximum hysteresis (absolute) versus temperature, for the $x=0.03$ composition. 


\subsection{In-situ Synchrotron X-ray Diffraction PTED MANUSCRIPT}

The potential contributions of electric field-induced phase transformations to the electro-mechanical behaviour of KBT-BMT ceramics were investigated further by conducting in-situ high-energy x-ray diffraction experiments. For $\mathrm{x}=0.3$, the diffraction patterns obtained at temperatures of $100{ }^{\circ} \mathrm{C}$ and below indicated the presence of coexisting tetragonal and pseudo-cubic phases, consistent with the results shown in Figures 1 and 2. In contrast, at a higher temperature of $150{ }^{\circ} \mathrm{C}$ the initial zero-field pattern corresponded to a single pseudo-cubic phase, as shown in Figure 10. This was found to transform into a mixture of pseudo-cubic and tetragonal phases, with phase fractions of approximately $63 \%$ and $37 \%$ respectively, at an electric field above $20 \mathrm{kV} / \mathrm{cm}$. These results confirm the presence of a substantial volume fraction of non-ergodic PNRs for this composition at $150{ }^{\circ} \mathrm{C}$, which transform irreversibly into the long-range ordered ferroelectric state upon poling. Similar observations of an irreversible electric field-induced transformation were also made for the $\mathrm{x}=0.8$ composition at room temperature, which explains the ferroelectric P-E loop of this pseudocubic composition (Figure S4). Laboratory XRD analysis of crushed sintered pellets of $\mathrm{x}=0.03$ indicated tetragonal phase persisted to $\sim 260^{\circ} \mathrm{C}$ ( Figure 2) ; this disparity is associated with the effects of grinding and release of matrix constraint.

(a)

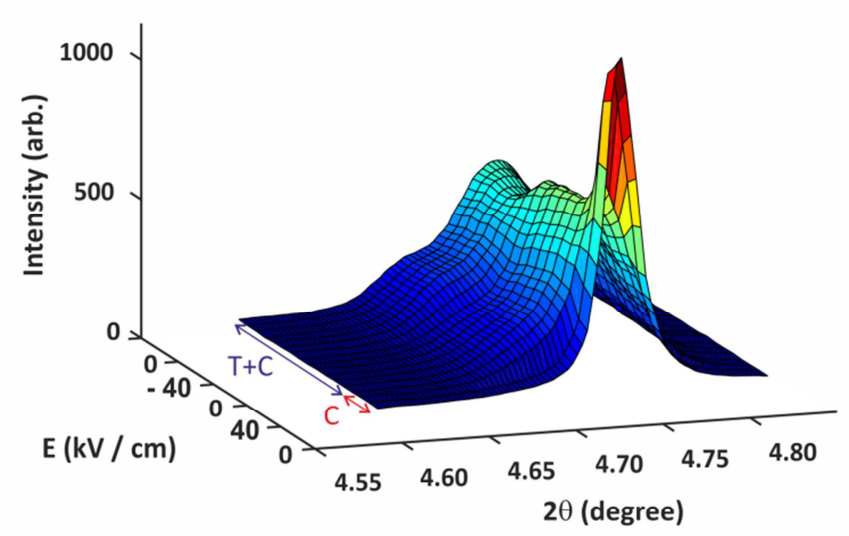

(b)
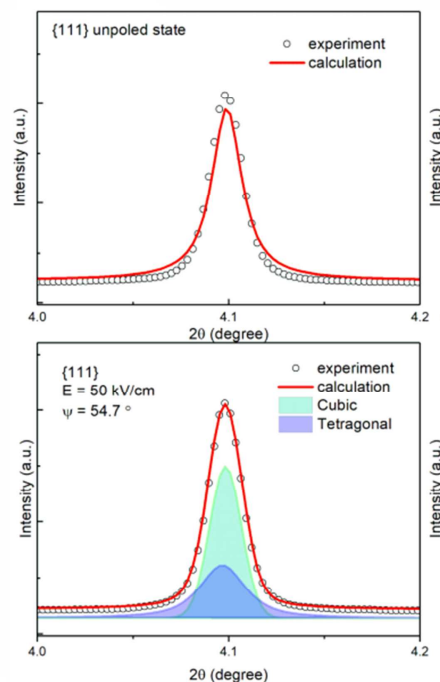
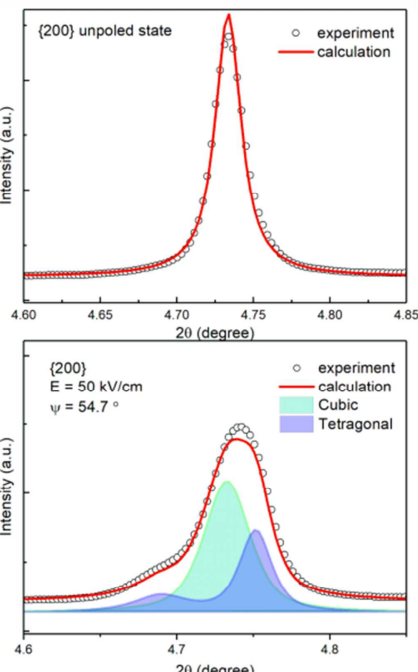

Figure 10. (a) Changes in $\{200\}_{p}$ diffraction peak profiles and (b) full-pattern fitting obtained from in-situ high energy XRD measurements under a cyclic electric field up to $40 \mathrm{kV} / \mathrm{cm}$ at $150^{\circ} \mathrm{C}$. Fullpattern fits were conducted at an azimuthal angle, $\psi$, of $54.7^{\circ}$, which is assumed to represent the strain- and texture-free state ${ }^{41,42}$. 


\section{Discussion}

Within the compositional range $0 \leq \mathrm{x} \leq 0.07$, the distinctive property trends in KBT-BMT arise for the following reasons: (a) co-existence of ferroelectric tetragonal and weakly polar pseudocubic phases which vary in relative proportion with changing overall composition, $\mathrm{x}$; (b) a structural transformation from mixed to single phasepseudo cubic on heating which can be reversed by application of an electric field.

The highest $d_{33}$ value occurs in the two phase field at a phase ratio of approximately 50/50 tetragonal/pseudocubic, corresponding to solid solution composition $\mathrm{x}=0.03$. Powder X-ray diffraction of samples prepared from crushed sintered pellets shows the transition to single phase cubic at $260{ }^{\circ} \mathrm{C}$ (Figure 2) but corresponding synchrotron data on dense ceramic pellets indicates only pseudocubic phase can be detected at $\sim 150^{\circ} \mathrm{C}$ (Figure 10). This points to phase stability and temperature range of stability of tetragonal KBMT being influenced bv microstructural matrix constraint effects.

Rietveld refinements point to a slightly higher $\mathrm{Mg}$ B-site occupancy in the pseudocubic phase (Table S1, Supplementary Information). Magnesium ions are known to be ferroelectrically inactive relative to titanium ions in a perovskite lattice. The higher $\mathrm{Mg}$ levels in pseudocubic KBMT would inhibit coherent long range polar order. However inferred compositional discrepancies between the two phases are below the detection limits of energy dispersive X-ray spectroscopy (EDX) using SEM or TEM analytical techniques.

The changes to polar length scales at $\sim 150^{\circ} \mathrm{C}$ are responsible for a weak inflection in in $\varepsilon_{\mathrm{r}}-\mathrm{T}$ plots of poled samples of KBMT and an increase in $\tan \delta$. However, full depolarisation $\left(\mathrm{T}_{\mathrm{d}}\right)$ of $\mathrm{x}=0.03$ is not observed until $\sim 220^{\circ} \mathrm{C}$ and is signified in Figure 4 by a peak in $\tan \delta .{ }^{32}$ Further heating results in a characteristic frequency-dependent dielectric relaxation peak due to the changing dynamics of dipole coupling under an a.c. field.

The temperatures at which P-E loops of ceramic pellets begin to show constriction (Figure 5) due to the non-ergodic to ergodic changeover are consistent with the structural transition temperature identified by synchrotron X-ray diffraction. In P-E loop measurements at $175{ }^{\circ} \mathrm{C}$ and $185{ }^{\circ} \mathrm{C}$, a reduction in polarisation at low fields is a consequence of the thermally induced change to weakly polar ergodic structure: at sufficient electric field the ferroelectric structure re-forms. The overall effect is P-E constriction.

The S-E loops show a change in shape above $150^{\circ} \mathrm{C}$ for a similar reason. The electric field-induced reverse transition of the ergodic to ferroelectric structure at $175^{\circ} \mathrm{C}$ or $185^{\circ} \mathrm{C}$ creates an additional strain contribution. Thus the slope of the $S_{\max }$ vs. T plots increases above $150{ }^{\circ} \mathrm{C}$ and a relatively high strain of 
$\sim 0.2 \%$ can be realized at $185{ }^{\circ} \mathrm{C}$ (the maximum temperature of the silicone oil bath). The time dependence of loss, or partial loss of field-induced long range order in KBMT after removal of the field is not known at this stage. Other $\mathrm{Pb}$-free piezoceramics show evidence of field induced transitions in $\mathrm{S}-\mathrm{E}$ response but for different reasons. For example, a field induced transition from mixed tetragonal and rhombohedral ferroelectric phases to a relaxor phase is reported at ambient temperatures for $\mathrm{NKN}$ modified NBT-BT or NBT-KBT. ${ }^{5,44}$

The structure-property relationships in KBMT illustrate that in contrast to other piezoelectric perovskite solid solutions neither a MPB nor a PPT is involved in maximising piezoelectric performance. Thus traditional concepts of polarisation rotation between two ferroelectric phases of differing symmetry, e.g. tetragonal and rhombohedral, as being a pre-requisite to minimise the energy barrier for domain wall movement and achieve enhanced performance in a piezoelectric solid solution appear not to apply to KBMT. Instead, the key determinant is a varying proportion of transformable weakly polar pseudocubic phase, coexisting with a ferroelectric tetragonal phase.

We attribute the enhancement in piezoelectric performance of $\operatorname{KBMT}(\mathrm{x}=0.03)$ relative to unmodified KBT to a reduction in energy barrier for ferroelectric domain wall movement in the tetragonal crystallites due to the beneficial effect of the co-existing transformable pseudocubic crystallites. The proportion of pseudocubic phase increases with increasing $\mathrm{x}$ (Table 1), having a value of $52 \% x=0.03$ (unpoled). The result is a $\sim 3$ fold increase in $d_{33}$ of poled samples relative to KBT at a $\sim 50 / 50$ ratio of each phase in KBMT. The explanation for this optimal ratio may relate to statistical probability of tetragonal and pseudocubic crystallites being intimately mixed. Local stress relief of dipole reorientation in tetragonal crystallites would be facilitated by adjacent pseudocubic crystallites. In KBT all crystallites are tetragonal with a moderately high $c / a$ ratio, making reorientation of dipoles energetically unfavourable (at ambient temperatures) due to microstructural clamping, giving a linear P-E response. The pseudocubic phase reduces this constraint and makes it easier for domains to re-orientate thereby enhancing extrinsic piezoelectric contributions, most effectively at a 50/50 ratio. The dilution of the tetragonal component below a level of $50 \%$ for $\mathrm{x}>0.03$ acts to lower $\mathrm{d}_{33}$ values. A progressive reduction in c/a ratio as $\mathrm{x}$ increases would also be anticipated to lower the energy for domain realignment, at the expense of reduce intrinsic contributions. However the composition-property trends across the range of solid solutions studied point to phase-proportion as being the dominant factor.

In terms of property comparisons with other $\mathrm{Pb}$-free piezoelectrics that retain performance to elevated temperatures, the best systems are the ferroelectric ceramics, $(\mathrm{Na}, \mathrm{K}, \mathrm{Li})\left(\mathrm{Nb}, \mathrm{Ta} \mathrm{O}_{3}-\mathrm{CaZrO}{ }_{3}\right.$ [NKLNT-CZ], (Na,K,Li) $\mathrm{NbO}_{3}-\mathrm{CaZrO}_{3}$ [NKLN-CZ], and $\mathrm{Na}_{0.5} \mathrm{~K}_{0.5} \mathrm{NbO}_{3}-\mathrm{BaZrO}_{3}-(\mathrm{Bi}, \mathrm{Li}) \mathrm{TiO}_{3}$ [NKN-BZBLT]. ${ }^{9,10,45,46}$ Compositional modifications of the base NKN composition in these systems favourably modify the temperature of a PPT, and in some cases creates a more diffuse PPT. In the original example 
of NKLNT-CZ, core-shell microstructures have an important bearing on properties, but no such segregation was evident from our TEM-EDX analysis of KBMT. Both NKLN-CZ and NKN-BZ-BLT have higher $d_{33}$ values than KBMT. However the maximum field-induced strains in KBMT are comparable to, or slightly higher than NKLN-5CZ, as is the depolarisation temperature ( $T_{\mathrm{d}}$ is just below $200{ }^{\circ} \mathrm{C}$ in NKLN-0.05CZ as opposed to $220{ }^{\circ} \mathrm{C}$ for KBMT), whilst the 'giant' strains of $\sim 0.4 \%$ at 40 $\mathrm{kV} / \mathrm{cm}$ reported for NKLNT-CZ are higher than for KBMT. ${ }^{46}$ The highest measurement temperature in this work, $\sim 185{ }^{\circ} \mathrm{C}$, gives strains of $\sim 0.2 \%$. There is no PPT in the temperature range of strain measurements $\left(20-185^{\circ} \mathrm{C}\right)$ for KBMT. The damaging consequences of a PPT on piezoelectric response after repeated thermal cycling through the phase transition has been reported for NKN-LT ${ }^{7}$. The diffuse nature of the PPT in NKLN-0.05CZ at temperatures slightly above room-temperature is such that although strains initially increase then decrease on heating above $25^{\circ} \mathrm{C}$, they vary by only $\pm 10 \%$ of their room-temperature value $(\sim 0.13 \%$ at $40 \mathrm{kV} / \mathrm{cm})$ up to a temperature of $175^{\circ} \mathrm{C}^{10}\left(T_{\mathrm{c}}\right.$ is $\left.<200^{\circ} \mathrm{C}\right)$ in single cycle measurements. This compares to a $\sim 30 \%$ linear increase in $\mathrm{S}_{\max }$ for $\mathrm{KBMT}$ (to $150{ }^{\circ} \mathrm{C}$ ); a number of commercial PZTs also exhibit a linear change in $S_{\max }$ with temperature. In contrast to the linear increase in strain with temperature for KBMT, strains in NKN-BZ-BLT decrease in a non-linear manner on heating from $25^{\circ} \mathrm{C}$ to $150{ }^{\circ} \mathrm{C} .44$

\section{Conclusions}

Structure-property relationships have been investigated for the ceramic system (1-x) $\mathrm{K}_{0.5} \mathrm{Bi}_{0.5} \mathrm{TiO}_{3^{-}}$ $x \mathrm{Bi}\left(\mathrm{Mg}_{0.5} \mathrm{Ti}_{0.5}\right) \mathrm{O}_{3}$. In contrast to traditional lead-containing or lead-free piezoceramics, optimum properties do not correspond to a morphotropic or polymorphic phase boundary. A maximum value of $\mathrm{d}_{33}$ piezoelectric charge coefficient occurs at $\mathrm{x}=0.03$, which lies within a mixed phase tetragonal and pseudocubic region of the phase diagram at an approximately $\sim 50: 50$ phase ratio. Anomalies in dielectric, ferroelectric and electromechanical properties at temperatures $\geq 150{ }^{\circ} \mathrm{C}$ in KBMT can be explained by a thermally induced transition from non-ergodic ferroelectric tetragonal to weakly polar ergodic relaxor state. Tetragonal KBMT can be regenerated by application of an electric field as confirmed by in situ synchrotron X-ray diffraction, a finding which explains the observed constriction in P-E loops and asymmetry in S-E loops at $\geq 150^{\circ} \mathrm{C}$.

\section{Conflict of interest}

There are no conflicts of interest to declare. 


\section{Acknowledgements}

Aurang Zeb thanks the Higher Education Commission of Pakistan and Islamia College Peshawar (Chartered University) for financial support. We wish to thank Research Councils UK for contributions to funding (EP/P015514/1) and thank the Diamond Light Source for access to beamline I11 (EE14322) that contributed to the results presented here. At Tsinghua University, this work was partially supported by the National Natural Science Foundation of China (Grant No. 51332002). Thanks are also expressed to Andrew Bell, Tim Comyn, James Bennett and other colleagues at Leeds for valuable advice.

\section{References}

(1) B. Jaffe, W. R. Cook, H. Jaffe, Piezoelectric ceramics; Academic Press: London, 1971.

(2) B. Noheda, D. E. Cox, G. Shirane, G. A. Gonzalo, L. E. Cross, S. E. Park, Appl. Phys. Lett., 74, (1999) 2059-2061.

(3) R. C. Turner, F. A. Fuierer, R. E. Newnham, T. R. Shrout, Appl. Acoust, 41 (1994) 299-324.

(4) T. Y. Ansell, D. P. Cann, E. Sapper, J. Rödel, J. Am. Ceram. Soc., 98 (2015) 455-463.

(5) J. Rödel, W. Jo, K. T. P. Seifert, E. M. Anton, T. Granzow, D. Damjanovic, J. Am. Ceram. Soc., 92 (2009) 1153-1177.

(6) Y. Guo, K. I. Kakimoto, H. Ohsato, Appl. Phys. Lett., 85 (2004) 4121.

(7) T. A. Skidmore, T. P. Comyn, S. J. Milne, Appl. Phys. Lett., 94 (2009) 222902.

(8) J.-F Li, K. Wang, F.-Y. Zhu, L. Q. Cheng, F.-Z. Yao, J. Am. Ceram. Soc., 96 (2013) 3677-3696.

(9) R. Wang, H. Bando, M. Itoh, IMF-ISAF Conf. Xi'an, China, 2009, DO-033.

(10) K. Wang, F.-Z. Yao, W. Jo, D. Gobeljic, V. V. Shvartsman, D. C. Lupascu, J.F. Li, J. Rödel, J. Adv. Funct. Mater., 23 (2013) 4079-4086.

(11) T. A. Skidmore, T. P. Comyn, A. J. Bell, F. Y. Zhu, S. J. Milne, IEEE Trans. Ultrason. Ferroelectr. Freq. Control, 58 (2011) 1819.

(12) K. Wang, J.-F. Li, J. J. Zhou, Appl. Phys. Express, 4 (2011) 061501.

(13) T. Takenaka, K.-I. Maruyama, K. Sakata, Jpn. J. Appl. Phys., , 30 (1991) 2236-2239.

(14) Y. Guo, Y. Liu, R. L. Withers, F. Brink, H. Chen, Chem. Mater., 23 (2011) 219-228.

(15) W. Jo, J. E. Daniels, J. L. Jones, X. Tan, P. A. Thomas, D. Damjanovic, J. Rödel, J. Appl. Phys., 109 (2011) 014110.

(16) C. Ma, X. Tan, E. Dul'kin, M.J. Roth, J. Appl. Phys., , 108 (2010) 104105. 
(17) I. Levin, I. M. Reaney, E. M. Anton,W. Jo, J.Rödel,S. Pokorny, L. A. Schmitt, H.-J. Kleebe, M.

Hinterstein, J. L. Jones, Phys. Rev. B 87 (2013) 024113.

(18) Y.-R. Zhang, J.-F. Li, B.-P. Zhang, C.-E. Peng, J. Appl. Phys., , 103 ( 2008) 074109.

(19) K. Yoshii, Y. Hiruma, H. Nagata, T. Takenaka, Jpn. J. Appl. Phys., 45(5B) (2006) 4493-4496.

(20) Y. Hiruma, H. Nagata, T. Takenaka, J. Appl. Phys., 104 (2008) 124106.

(21) A. J. Royles, A. J. Bell, A. P. Jephcoat, A. K. Kleppe, S. J. Milne, T. P. Comyn, Appl. Phys. Lett., 97 (2010) 132909.

(22) H. Simons, J. E. Daniels, J. A. Glaum, A. J. Studer, J. L. Jones, M. Hoffman, Appl. Phys. Lett., 102 (2013) 062902.

(23) E.-M. Anton, W. Jo, D. Damjanovic, J. Rödel, J. Appl. Phys., 110 (2011) 094108.

[24] Y. Hiruma, Y. Makiuchi, R. Aoyagi, H. Nagata, T. Takenaka, Ceram. Trans., 174 (2005) 139.

(25) H. Nagata, M. Yoshida, Y. Makiuchi, T. Takenaka, Jpn. J. Appl. Phys., 42 (2003) 7401-7403.

(26) S.-T. Zhang, A. B. Kounga, E. Aulbach, T. Granzow, W. Jo, H.-J. Kleebe, J. Rödel, J. Appl. Phys., 103 (2008) 034107.

(27) J. E. Daniels, W. Jo, J. Rödel, V. Honkimäki, J. L. Jones, Acta Mater., 58 ( 2010) 2103-2111.

(28) J. Hao, B. Shen, J. Zhai, H. Chen, J. Appl. Phys., 115 (2014) 034101.

(29) H. Nagata, K. Tabuchi, T. Takenaka, Jpn. J. Appl. Phys., 52 (2013) 09KD05.

(30) Y. Hiruma, R. Aoyagi, H. Nagata, T. Takenaka, Jpn. J. Appl. Phys., 44 (2005) 5040-5044.

(31) A. Zeb, S. J. Milne, J. Am. Ceram. Soc., 97 (2014) 2413-2415.

(32) A. Zeb, D. A. Hall, S. J. Milne, J. Mater. Sci.: Mater. Electron., 26 (2015) 9516-9521.

(33) P. Jaita, P. Jarupoom, R. Yimnirun, G. Rujijanagul, D. P. Cann, Ceram. Int., 42 (2016) 1594015949.

(34) S. P. Thompson, J. E. Parker, J. Potter, T. P. Hill, A. Birt, T. M. Cobb, F. Yuan, C. C. Tang, Review Sci. Inst., 80 (2009) 075107-1.

(35) A. C. Larson and R. B. Von Dreele, Los Alamos National Laboratory Report No. LAUR 86-748, 2004 (unpublished).

(36) M. Chen, Q. Xu, B. H. Kima, B. K. Ahn, J. H. Ko, W. J. Kang, O. J. Nam, J. Eur. Ceram. Soc., 28 (2008) 843-849.

(37) B. Wylie-van Eerd, D. Damjanovic, N. Klein, N. Setter, J. Trodahl, J. Phys. Rev. B, 82 ( 2010) 104112.

(38) D. A. Hall, M. M. Ben-Omran, P. J. Stevenson, J. Phys: Condens. Matt., 10 (1998), 461-476.

(39) D. A. Hall, J. Mater. Sci., 36 (2001) 4575-4601.

(40) D. A. Hall, Ferroelectrics, , 223 (1999) 319-328. 
(41) D.A. Hall, A. Steuwer, B. Cherdhirunkorn, P.J. Withers, T. Mori, J. Mech. Phys. Solids 53 (2005) 249-260

(42) J. Filik et al., J. Appl. Cryst. 50 (2017) 959-966

(43) T. Roncal Herrero, J. Harrington, A. Zeb S. J. Milne, A. P. Brown, Acta Materialia 158 (2018) 422429

(44) W. Jo, T. Granzow, E. Aulbach, J. Rödel, D. Damjanovic, J. Appl. Phys., 105 ( 2009) 094102.

(45) S.-Y. Choi, S. J. Jeong, D.-S. Lee, M.-S. Kim, J.-S. Lee, J. H. Cho, B. I. Kim, Y. Ikuhara, Chem. Mater., 24 (2012) 3363.

(46) R. Wang, K. Wang, F. Yao, J. F. Li, F. H. Schader, K. G. Webber, W. Jo, J. Rödel, J. Am. Ceram. Soc.,, 98, (2015) 2177-2182. 


\section{SUPPLEMENTARY INFORMATION}

Table S1. Refined crystal structure for each composition

$\mathrm{x}=0 \quad$ Tetragonal

\begin{tabular}{|c|c|c|c|c|c|c|}
\hline Site & $\mathrm{x}$ & $\mathrm{y}$ & $\mathrm{z}$ & $\begin{array}{c}\mathrm{U}_{\text {iso }} \\
\left(100 \mathrm{x}^{2}\right)\end{array}$ & $\begin{array}{c}\text { Nominal } \\
\text { occupancy }\end{array}$ & $\begin{array}{c}\text { Refined } \\
\text { occupancy }\end{array}$ \\
\hline $\mathrm{K}(+1)$ & 0 & 0 & 0 & $3.02(2)$ & 0.5 & $0.507(3)$ \\
\hline $\mathrm{Bi}(+3)$ & 0 & 0 & 0 & $3.02(2)$ & 0.5 & $0.493(3)$ \\
\hline $\mathrm{Ti}(+4)$ & 0.5 & 0.5 & $0.4401(5)$ & $0.90(5)$ & 1 & $1.019(5)$ \\
\hline $\mathrm{O} 1(-2)$ & 0.5 & 0.5 & $-0.079(2)$ & $0.23(5)$ & 1 & $1.08(1)$ \\
\hline $\mathrm{O} 2(-2)$ & 0.5 & 0 & $0.395(1)$ & $2.34(7)$ & 1 & $1.03(2)$ \\
\hline
\end{tabular}

$\mathrm{x}=0.02$ Tetragonal

\begin{tabular}{|c|c|c|c|c|c|c|}
\hline Site & $\mathrm{x}$ & $\mathrm{y}$ & $\mathrm{z}$ & $\begin{array}{c}\mathrm{U}_{\text {iso }} \\
\left(100 \mathrm{x}^{2}\right)\end{array}$ & $\begin{array}{c}\text { Nominal } \\
\text { occupancy }\end{array}$ & $\begin{array}{c}\text { Refined } \\
\text { occupancy }\end{array}$ \\
\hline $\mathrm{K}(+1)$ & 0 & 0 & 0 & $2.60(5)$ & 0.49 & $0.496(3)$ \\
\hline $\mathrm{Bi}(+3)$ & 0 & 0 & 0 & $2.60(5)$ & 0.51 & $0.504(3)$ \\
\hline $\mathrm{Ti}(+4)$ & 0.5 & 0.5 & $0.4385(4)$ & $2.12(6)$ & 0.99 & $0.992(3)$ \\
\hline $\mathrm{Mg}(+2)$ & 0.5 & 0.5 & $0.4385(4)$ & $2.12(6)$ & 0.01 & $0.008(3)$ \\
\hline $\mathrm{O} 1(-2)$ & 0.5 & 0.5 & $-0.0805(6)$ & $0.14(8)$ & 1 & $1.03(7)$ \\
\hline $\mathrm{O} 2(-2)$ & 0.5 & 0 & $0.4012(7)$ & $0.66(8)$ & 1 & $1.00(9)$ \\
\hline
\end{tabular}

Cubic

\begin{tabular}{|c|c|c|c|c|c|c|}
\hline Site & $\mathrm{x}$ & $\mathrm{y}$ & $\mathrm{z}$ & $\begin{array}{c}\mathrm{U}_{\text {iso }} \\
\left(100 \mathrm{x}^{2}\right)\end{array}$ & $\begin{array}{c}\text { Nominal } \\
\text { occupancy }\end{array}$ & $\begin{array}{c}\text { Refined } \\
\text { occupancy }\end{array}$ \\
\hline $\mathrm{K}(+1)$ & 0 & 0 & 0 & $3.14(3)$ & 0.49 & $0.498(4)$ \\
\hline
\end{tabular}




\begin{tabular}{|c|c|c|c|c|c|c|}
\hline $\mathrm{Bi}(+3)$ & 0 & 0 & 0 & $\mathrm{~A} \mid \mathrm{CC} 3.14(3)$ & $0.51 \mathrm{CH}$ & $0.502(4)$ \\
\hline $\mathrm{Ti}(+4)$ & 0.5 & 0.5 & 0.5 & $1.97(2)$ & 0.99 & $0.989(3)$ \\
\hline $\mathrm{Mg}(+2)$ & 0.5 & 0.5 & 0.5 & $1.97(2)$ & 0.01 & $0.011(3)$ \\
\hline O1 (-2) & 0.5 & 0.5 & 0 & $3.3(6)$ & 1 & $0.98(8)$ \\
\hline
\end{tabular}

ctd

Table $\mathrm{S} 1$

$\mathrm{x}=0.03$ Tetragonal

\begin{tabular}{|c|c|c|c|c|c|c|}
\hline Site & $\mathrm{x}$ & $\mathrm{y}$ & $\mathrm{z}$ & $\begin{array}{c}\mathrm{U}_{\text {iso }} \\
\left(100 \times \AA^{2}\right)\end{array}$ & $\begin{array}{c}\text { Nominal } \\
\text { occupancy }\end{array}$ & $\begin{array}{c}\text { Refined } \\
\text { occupancy }\end{array}$ \\
\hline $\mathrm{K}(+1)$ & 0 & 0 & 0 & $3.26(4)$ & 0.485 & $0.488(2)$ \\
\hline $\mathrm{Bi}(+3)$ & 0 & 0 & 0 & $3.26(4)$ & 0.515 & $0.512(2)$ \\
\hline $\mathrm{Ti}(+4)$ & 0.5 & 0.5 & $0.4561(8)$ & $1.35(3)$ & 0.985 & $0.991(3)$ \\
\hline $\mathrm{Mg}(+2)$ & 0.5 & 0.5 & $0.4561(8)$ & $1.35(3)$ & 0.015 & $0.009(3)$ \\
\hline $\mathrm{O} 1(-2)$ & 0.5 & 0.5 & $-0.0639(3)$ & $5.78(6)$ & 1 & $1.000(3)$ \\
\hline $\mathrm{O} 2(-2)$ & 0.5 & 0 & $0.4496(2)$ & $1.75(5)$ & 1 & $1.001(4)$ \\
\hline
\end{tabular}

Cubic

\begin{tabular}{|c|c|c|c|c|c|c|}
\hline Site & $\mathrm{x}$ & $\mathrm{y}$ & $\mathrm{z}$ & $\begin{array}{c}\mathrm{U}_{\text {iso }} \\
\left(100 \mathrm{x}^{2}\right)\end{array}$ & $\begin{array}{c}\text { Nominal } \\
\text { occupancy }\end{array}$ & $\begin{array}{c}\text { Refined } \\
\text { occupancy }\end{array}$ \\
\hline $\mathrm{K}(+1)$ & 0 & 0 & 0 & $4.70(3)$ & 0.485 & $0.487(4)$ \\
\hline $\mathrm{Bi}(+3)$ & 0 & 0 & 0 & $4.70(3)$ & 0.515 & $0.513(4)$ \\
\hline $\mathrm{Ti}(+4)$ & 0.5 & 0.5 & 0.5 & $1.45(4)$ & 0.985 & $0.982(4)$ \\
\hline $\mathrm{Mg}(+2)$ & 0.5 & 0.5 & 0.5 & $1.45(4)$ & 0.015 & $0.018(4)$ \\
\hline $\mathrm{O} 1(-2)$ & 0.5 & 0.5 & 0 & $3.85(6)$ & 1 & $1.009(4)$ \\
\hline
\end{tabular}

$\mathrm{x}=0.04$ Tetragonal

\begin{tabular}{|c|c|c|c|c|c|c|}
\hline Site & $\mathrm{x}$ & $\mathrm{y}$ & $\mathrm{z}$ & $\mathrm{U}_{\text {iso }}$ & Nominal & Refined \\
\hline
\end{tabular}




\begin{tabular}{|c|c|c|c|c|c|c|}
\cline { 5 - 7 } & & & & $\mathrm{C}\left(100 \times \AA^{2}\right)$ & occupancy & occupancy \\
\hline $\mathrm{K}(+1)$ & 0 & 0 & 0 & $2.48(9)$ & 0.48 & $0.483(3)$ \\
\hline $\mathrm{Bi}(+3)$ & 0 & 0 & 0 & $2.48(9)$ & 0.52 & $0.517(3)$ \\
\hline $\mathrm{Ti}(+4)$ & 0.5 & 0.5 & $0.566(1)$ & $1.56(5)$ & 0.98 & $0.991(3)$ \\
\hline $\mathrm{Mg}(+2)$ & 0.5 & 0.5 & $0.566(1)$ & $1.56(5)$ & 0.02 & $0.009(3)$ \\
\hline $\mathrm{O} 1(-2)$ & 0.5 & 0.5 & $0.060(8)$ & $4.99(8)$ & 1 & $1.01(1)$ \\
\hline $\mathrm{O} 2(-2)$ & 0.5 & 0 & $0.618(2)$ & $1.84(4)$ & 1 & $1.03(2)$ \\
\hline
\end{tabular}

Cubic

\begin{tabular}{|c|c|c|c|c|c|c|}
\hline Site & $\mathrm{x}$ & $\mathrm{y}$ & $\mathrm{z}$ & $\begin{array}{c}\mathrm{U}_{\text {iso }} \\
\left(100 \mathrm{x}^{2}\right)\end{array}$ & $\begin{array}{c}\text { Nominal } \\
\text { occupancy }\end{array}$ & $\begin{array}{c}\text { Refined } \\
\text { occupancy }\end{array}$ \\
\hline $\mathrm{K}(+1)$ & 0 & 0 & 0 & $3.64(9)$ & 0.48 & $0.483(3)$ \\
\hline $\mathrm{Bi}(+3)$ & 0 & 0 & 0 & $3.64(9)$ & 0.52 & $0.517(3)$ \\
\hline $\mathrm{Ti}(+4)$ & 0.5 & 0.5 & 0.5 & $1.39(7)$ & 0.98 & $0.972(2)$ \\
\hline $\mathrm{Mg}(+2)$ & 0.5 & 0.5 & 0.5 & $1.39(7)$ & 0.02 & $0.028(2)$ \\
\hline $\mathrm{O} 1(-2)$ & 0.5 & 0.5 & 0 & $3.40(2)$ & 1 & $0.992(4)$ \\
\hline
\end{tabular}

ctd

Table S1

Tetragonal

$\mathrm{x}=0.07$

\begin{tabular}{|c|c|c|c|c|c|c|}
\hline Site & $\mathrm{x}$ & $\mathrm{y}$ & $\mathrm{z}$ & $\begin{array}{c}\mathrm{U}_{\text {iso }} \\
\left(100 \mathrm{x}^{2}\right)\end{array}$ & $\begin{array}{c}\text { Nominal } \\
\text { occupancy }\end{array}$ & $\begin{array}{c}\text { Refined } \\
\text { occupancy }\end{array}$ \\
\hline $\mathrm{K}(+1)$ & 0 & 0 & 0 & $2.22(12)$ & 0.465 & $0.471(5)$ \\
\hline $\mathrm{Bi}(+3)$ & 0 & 0 & 0 & $2.22(12)$ & 0.535 & $0.529(5)$ \\
\hline $\mathrm{Ti}(+4)$ & 0.5 & 0.5 & $0.560(1)$ & $1.81(17)$ & 0.965 & $0.989(4)$ \\
\hline $\mathrm{Mg}(+2)$ & 0.5 & 0.5 & $0.560(1)$ & $1.81(17)$ & 0.035 & $0.011(4)$ \\
\hline $\mathrm{O} 1(-2)$ & 0.5 & 0.5 & $0.026(2)$ & $4.42(11)$ & 1 & $0.98(2)$ \\
\hline $\mathrm{O} 2(-2)$ & 0.5 & 0 & $0.639(3)$ & $4.75(31)$ & 1 & $0.99(3)$ \\
\hline
\end{tabular}

Cubic

\begin{tabular}{|c|c|c|c|c|c|c|}
\hline Site & $\mathrm{x}$ & $\mathrm{y}$ & $\mathrm{z}$ & $\begin{array}{c}\mathrm{U}_{\text {iso }} \\
\left(100 \mathrm{x}^{2}\right)\end{array}$ & $\begin{array}{c}\text { Nominal } \\
\text { occupancy }\end{array}$ & $\begin{array}{c}\text { Refined } \\
\text { occupancy }\end{array}$ \\
\hline $\mathrm{K}(+1)$ & 0 & 0 & 0 & $3.32(5)$ & 0.465 & $0.467(2)$ \\
\hline $\mathrm{Bi}(+3)$ & 0 & 0 & 0 & $3.32(5)$ & 0.535 & $0.533(2)$ \\
\hline $\mathrm{Ti}(+4)$ & 0.5 & 0.5 & 0.5 & $1.07(4)$ & 0.965 & $0.949(1)$ \\
\hline $\mathrm{Mg}(+2)$ & 0.5 & 0.5 & 0.5 & $1.07(4)$ & 0.035 & $0.051(1)$ \\
\hline $\mathrm{O} 1(-2)$ & 0.5 & 0.5 & 0 & $1.44(6)$ & 1 & $1.006(3)$ \\
\hline
\end{tabular}



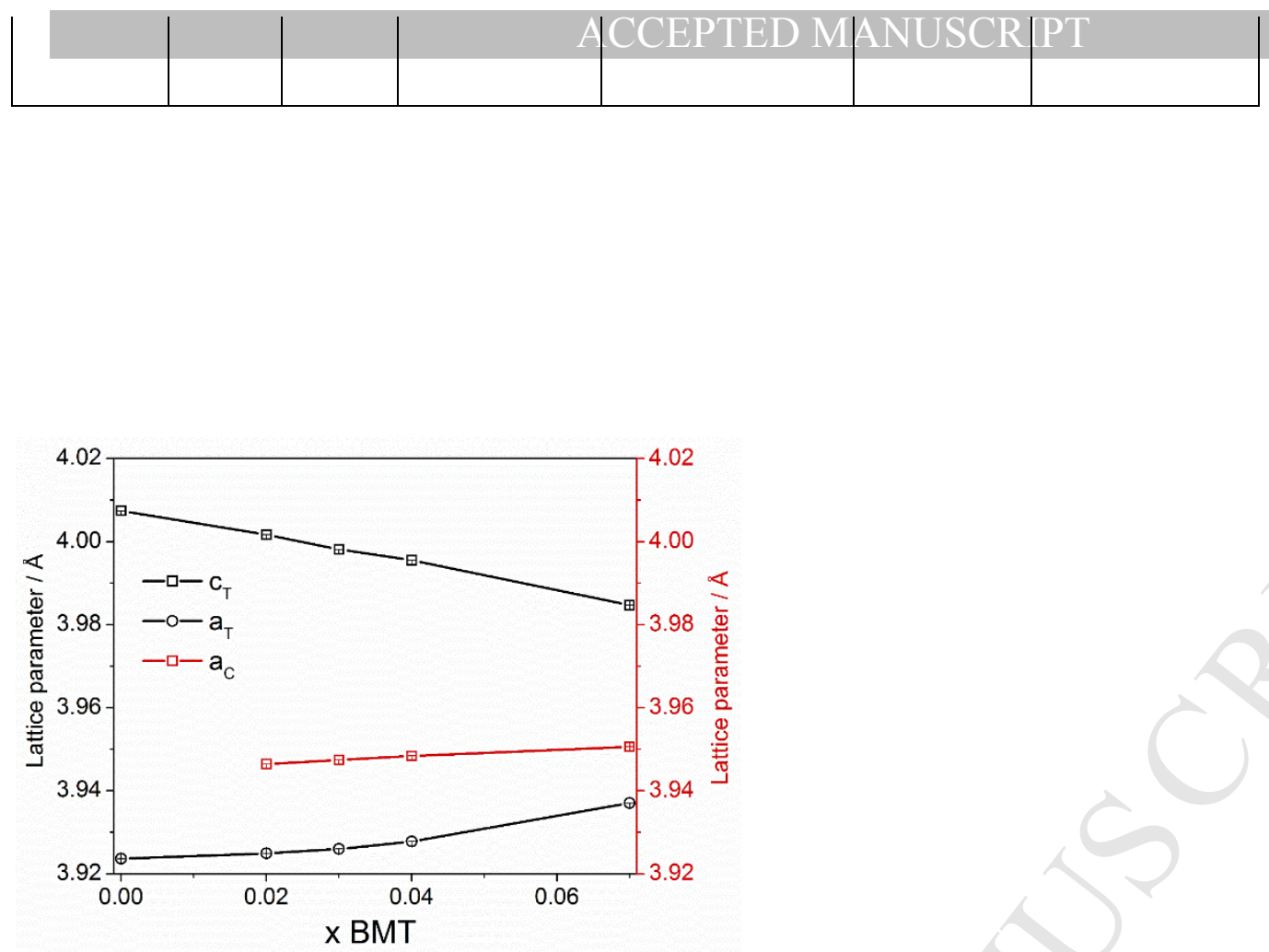

Figure S1. Lattice parameters obtained from the Rietveld refinements of the high resolution synchrotron diffraction data. 

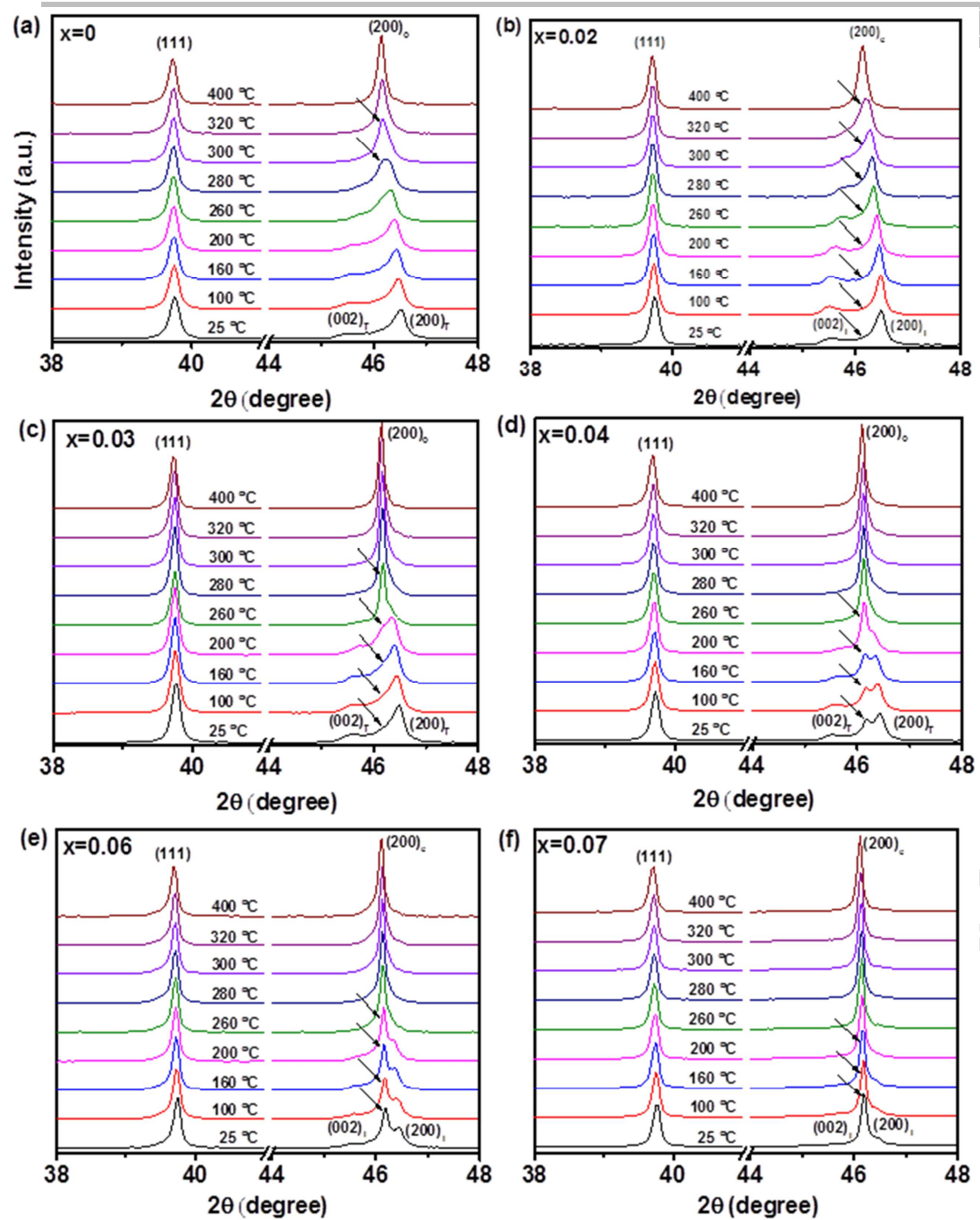

Figure S2. High temperature X-ray diffraction patterns used to construct the phase diagram ( arrow indicates cubic 200 peak). 

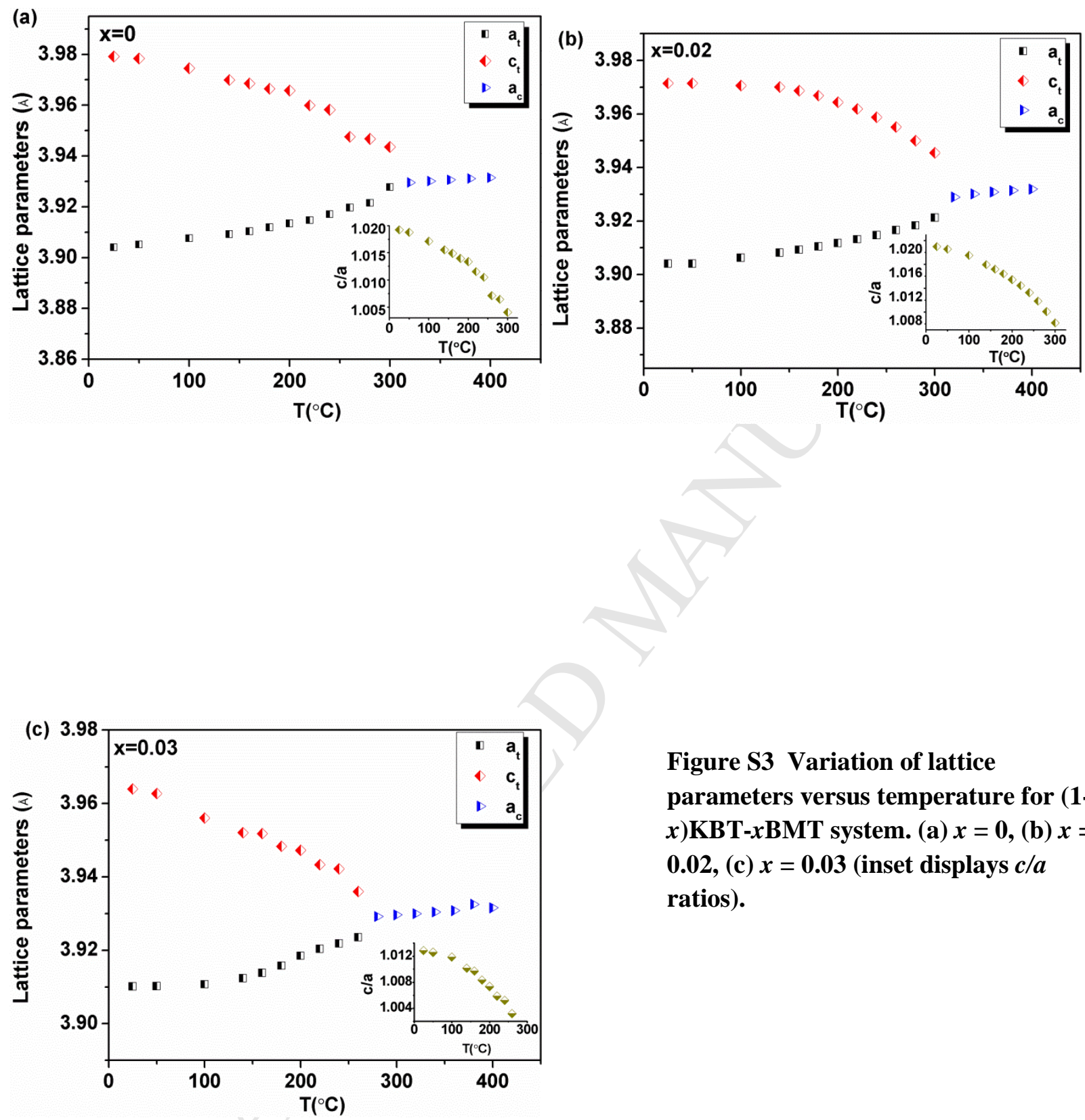

Figure S3 Variation of lattice parameters versus temperature for (1$x)$ KBT- $x$ BMT system. (a) $x=0$, (b) $x=$ 0.02 , (c) $x=0.03$ (inset displays $c / a$ ratios). 
(a)

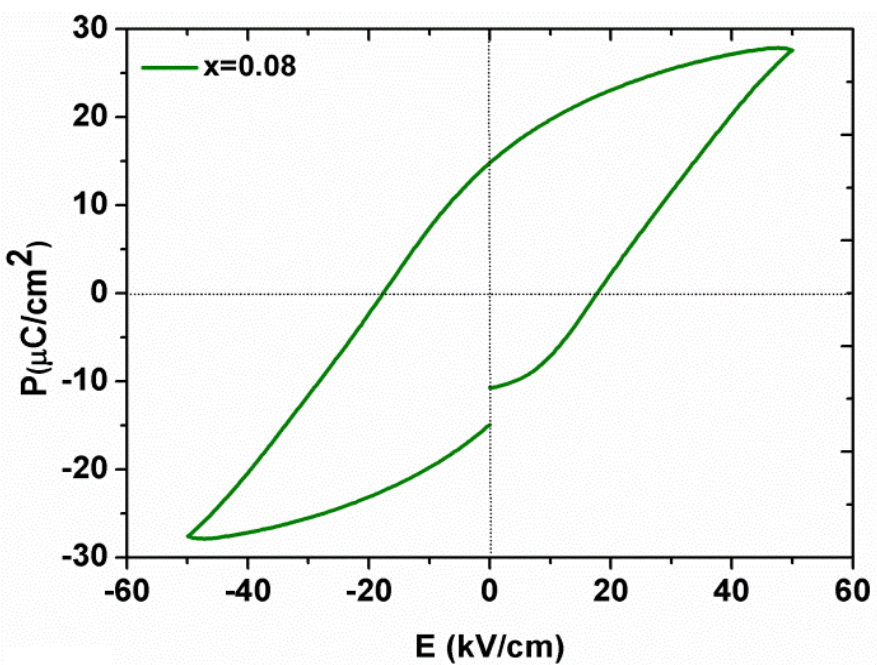

(b)

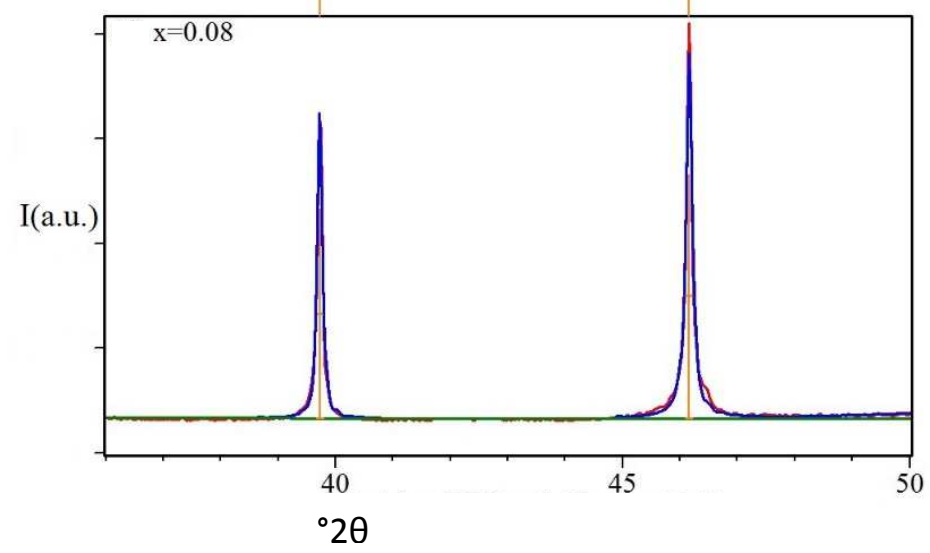

Figure S4. (a) Polarisation-electric field loop (room-temperature) for $x=0.08$; (b) XRD pattern highlighting the 111 and 200 reflections. 


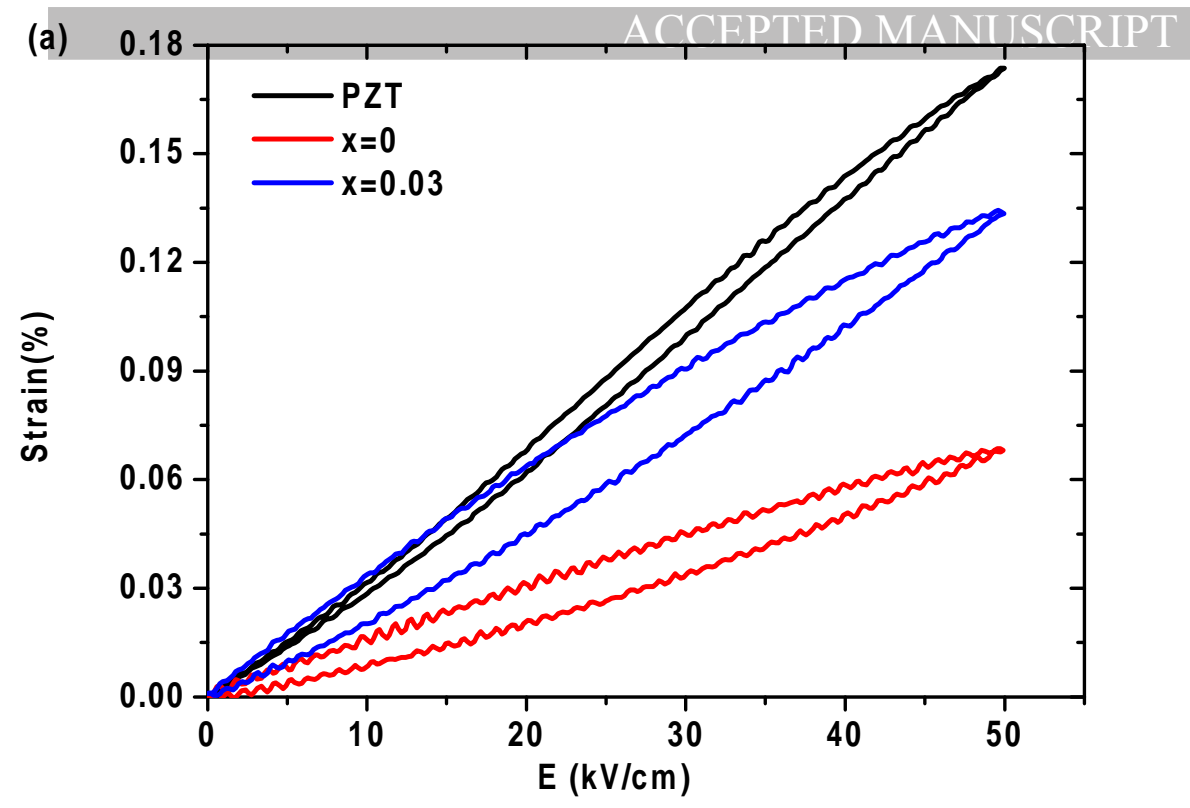

Figure S5 Electric field induced strain (room-temperature) for $\mathrm{x}=0,0.03$ and a low-hysteresis hard commercial PZT (PZT 806 Morgan Advanced Materials)

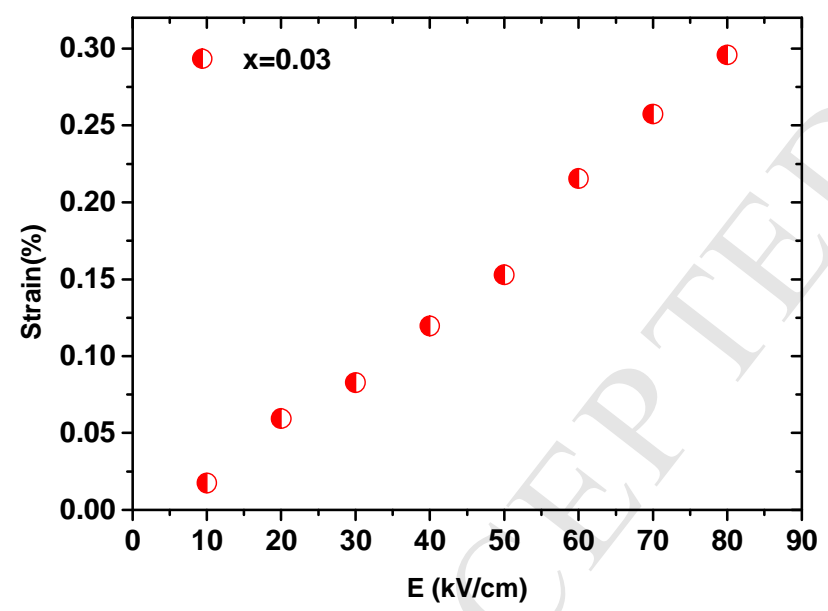

Figure S6 Strain versus incremental electric field strength for $\mathrm{x}=\mathbf{0 . 0 3}$ 


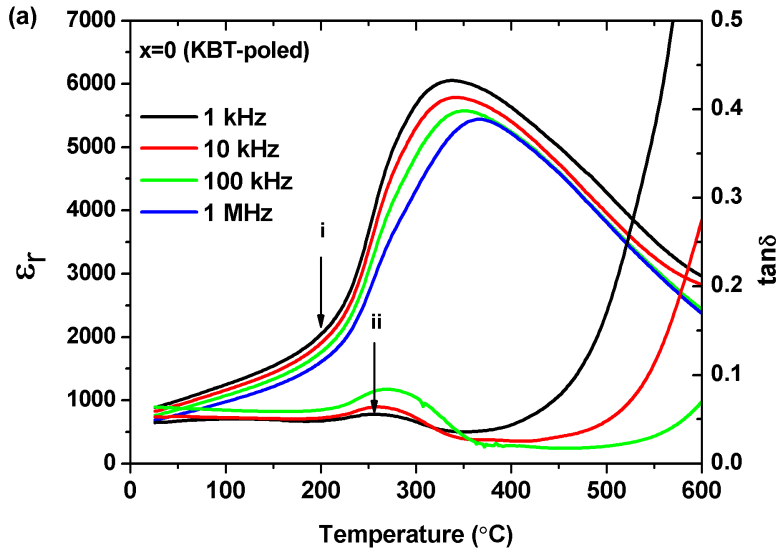




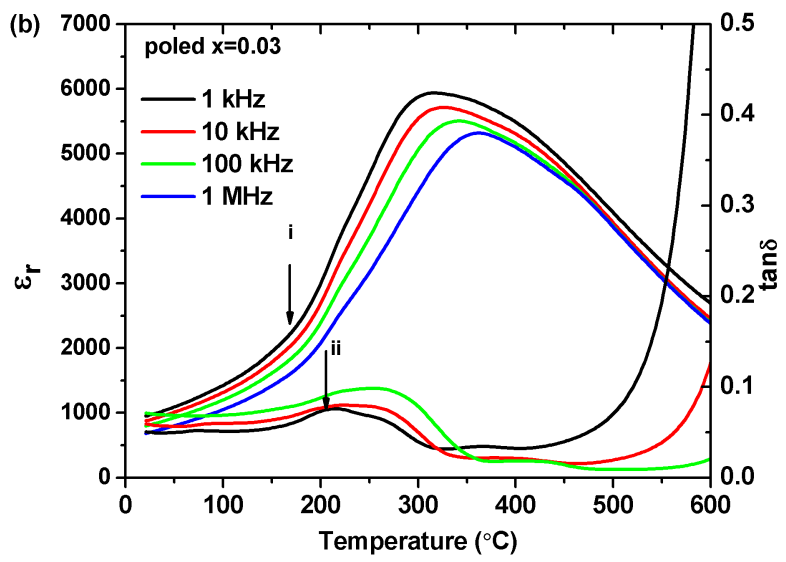



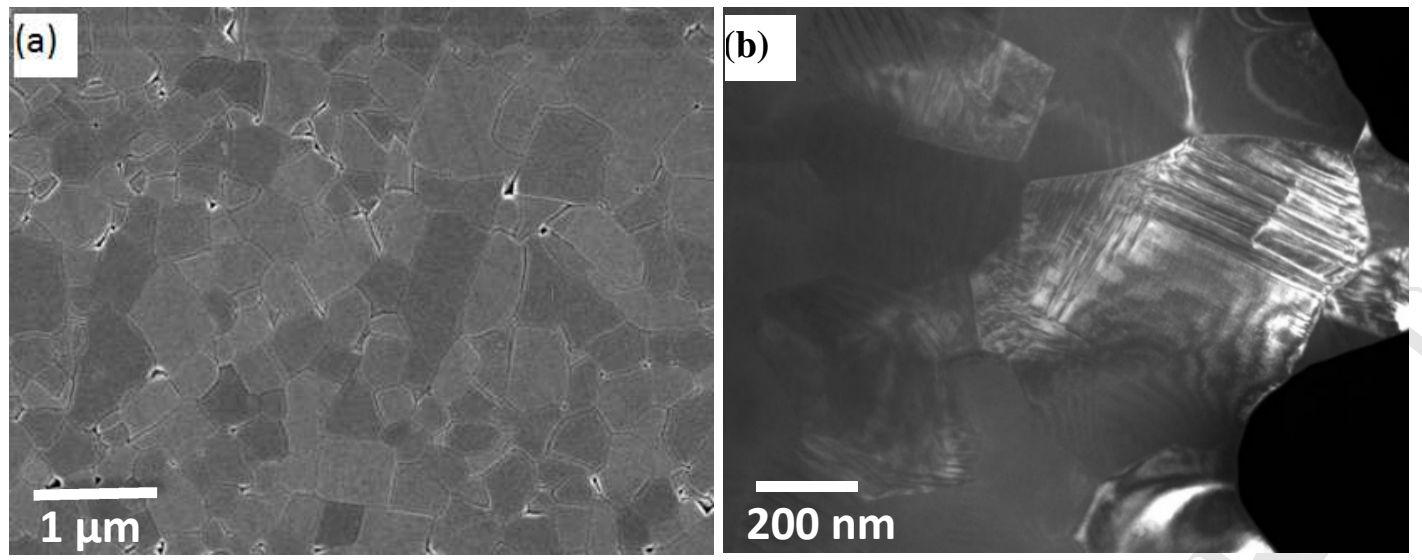

Figure 3. a) SEM micrograph of $x=0.03$ showing the submicron grain size. b) TEM micrograph (unheated sample) showing a tetragonal domain structure in a proportion of the grains. Other non-domain structured grains may be pseudocubic, or tetragonal at differing orientations. 


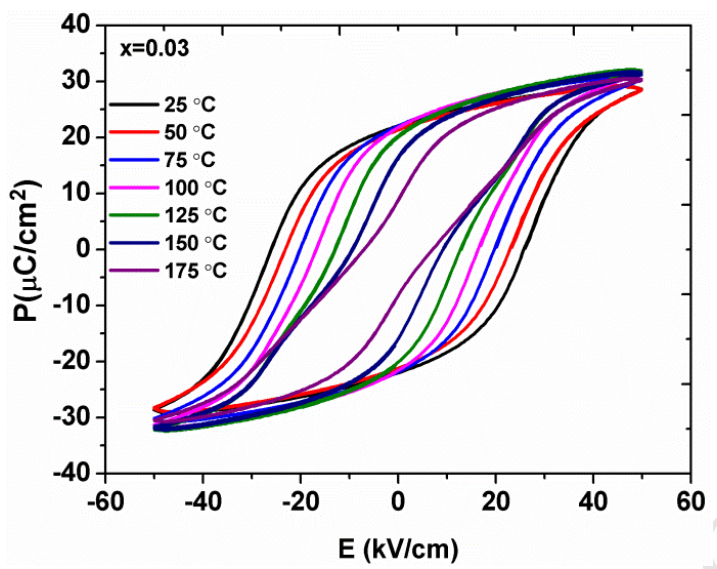

Figure 5. Polarization-electric field loops as a function of temperature for $\boldsymbol{x}=\mathbf{0 . 0 3}$ (50 $\mathrm{kV} / \mathrm{cm}$ ) showing partial constriction at $175^{\circ} \mathrm{C}$ due to loss of low-field polarisation resulting from the onset of the change from ferroelectric to ergodic relaxor. 

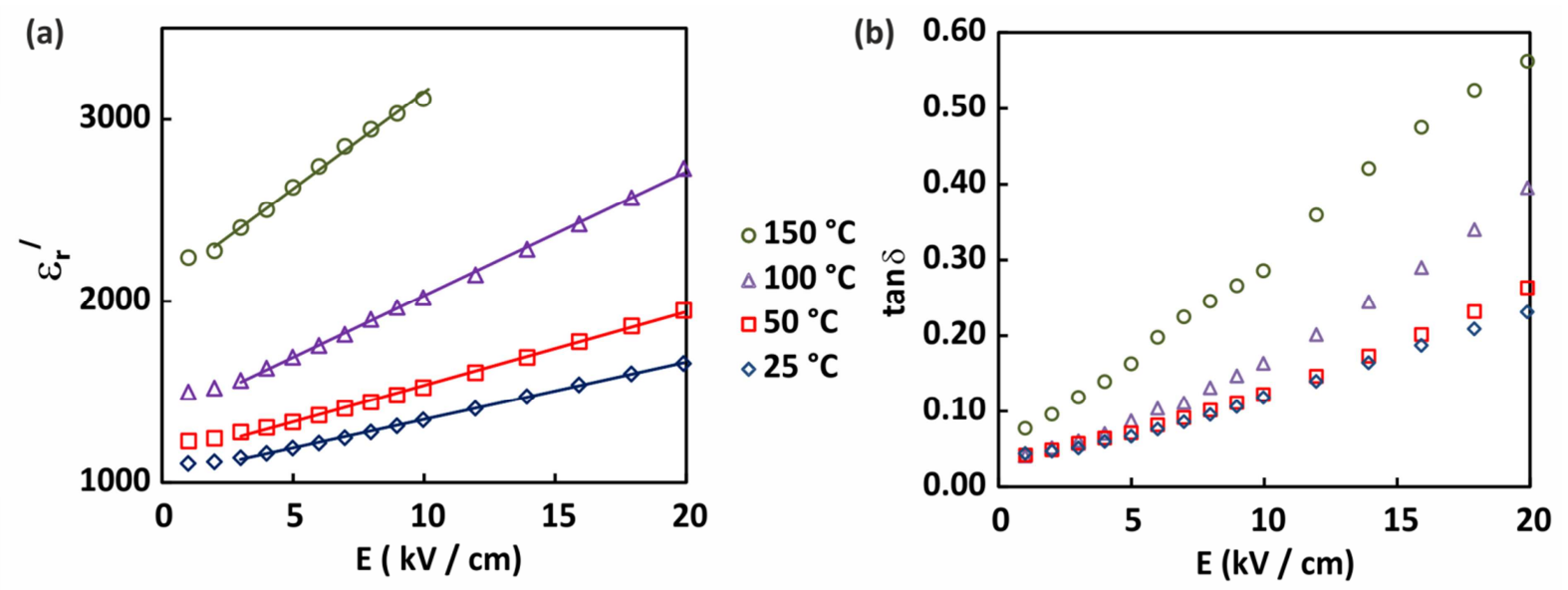

Figure 6. a) Nonlinear dielectric permittivity, and b) loss tangent data for $x=0.03$ ceramics measured over a range of electric field amplitudes and temperatures. 


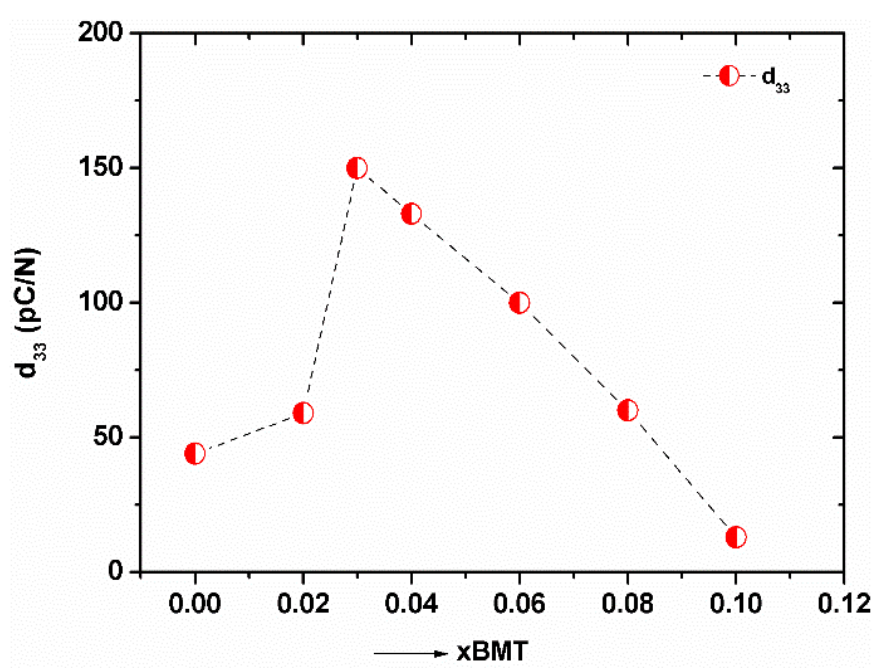

Figure 7. Variation of piezoelectric charge coefficient, $d_{33}$, versus $x$ for the KBMT system. 


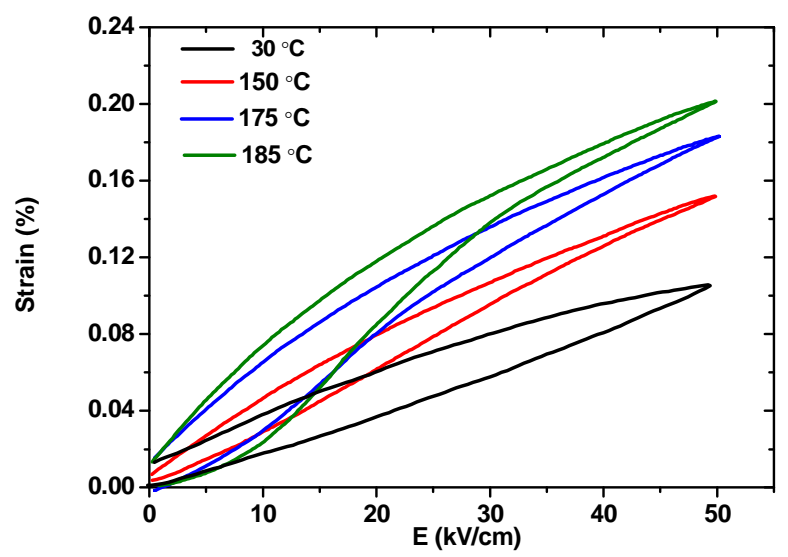

Figure 8. Unipolar S-E loops for $x=0.03$ showing elliptical loops with low hysteresis for temperatures up to $150{ }^{\circ} \mathrm{C}$ followed by a change in shape at $175{ }^{\circ} \mathrm{C}$ and $185{ }^{\circ} \mathrm{C}$ with increased hysteresis (span in $\mathrm{S}$ values). 

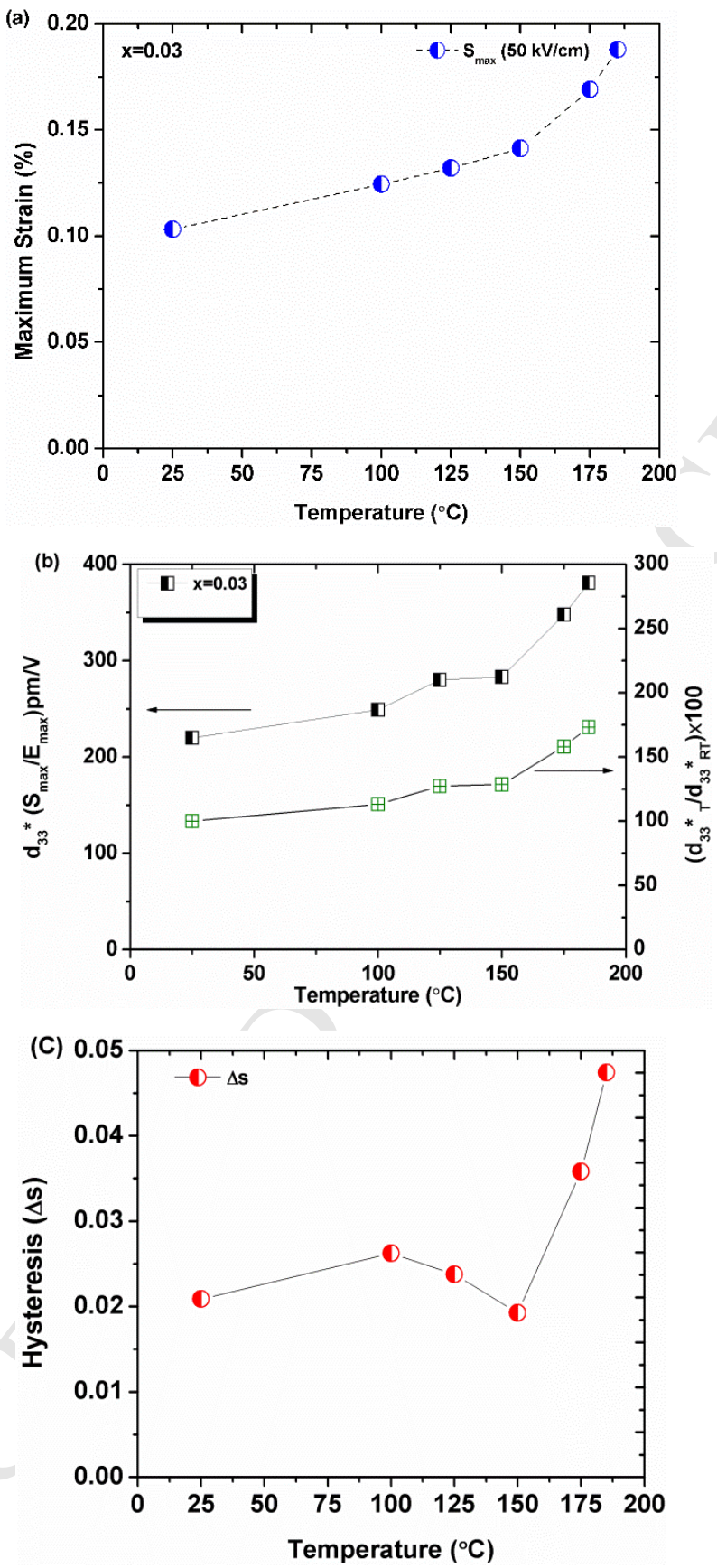

Figure 9. a) Temperature-dependent unipolar strain, $S_{\max }$ at $50 \mathrm{kV} / \mathrm{cm}(1 \mathrm{~Hz})$, b) temperature variation of effective $d_{33} *\left(\mathrm{~S}_{\max } / \mathrm{E}_{\max }\right)$ and normalized values, $\left.d_{33} * \mathrm{~T} / d_{33} *_{\mathrm{RT}} \mathrm{c}\right)$ strain maximum hysteresis (absolute) versus temperature, for the $\mathrm{x}=0.03$ composition. 
(a)

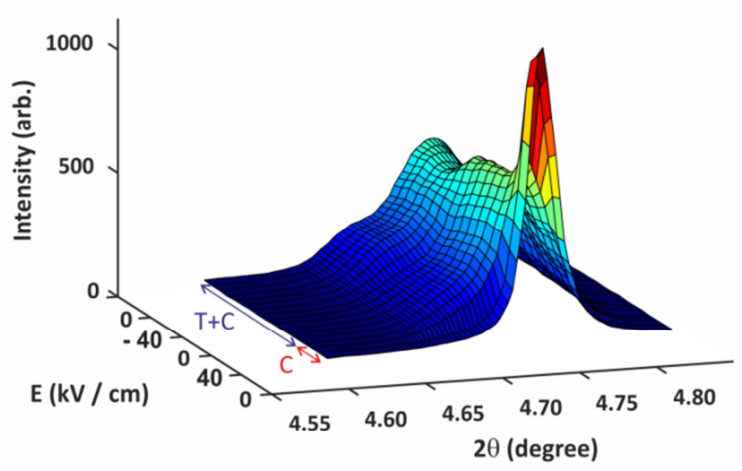

(b)
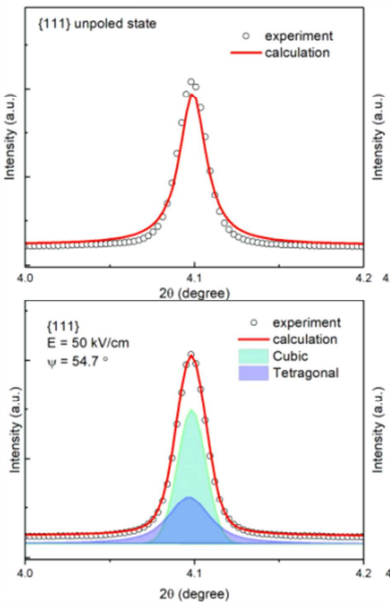
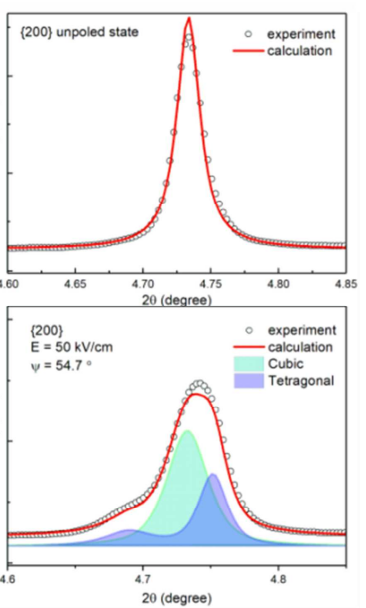

Figure 10. (a) Changes in $\{200\}_{\mathrm{p}}$ diffraction peak profiles and (b) full-pattern fitting obtained from in-situ high energy XRD measurements under a cyclic electric field up to $40 \mathrm{kV} / \mathrm{cm}$ at $150^{\circ} \mathrm{C}$. Full-pattern fits were conducted at an azimuthal angle, $\psi$, of $54.7^{\circ}$, which is assumed to represent the strain- and texture-free state $[41,42]$. 


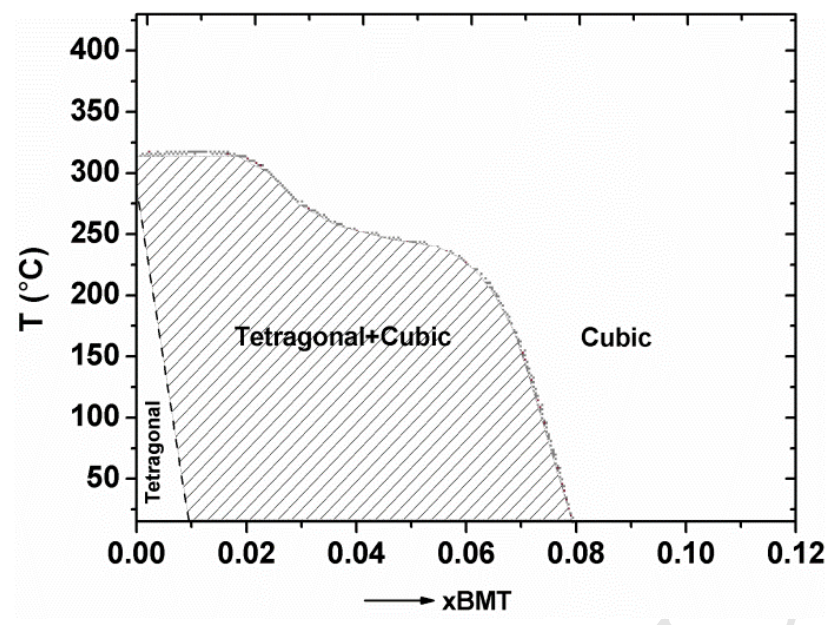

Figure 2. Phase diagram for the KBMT ceramic system based on XRD of crushed sintered pellets. The phase indicated as cubic by XRD is subsequently shown to be pseudocubic (see text). 


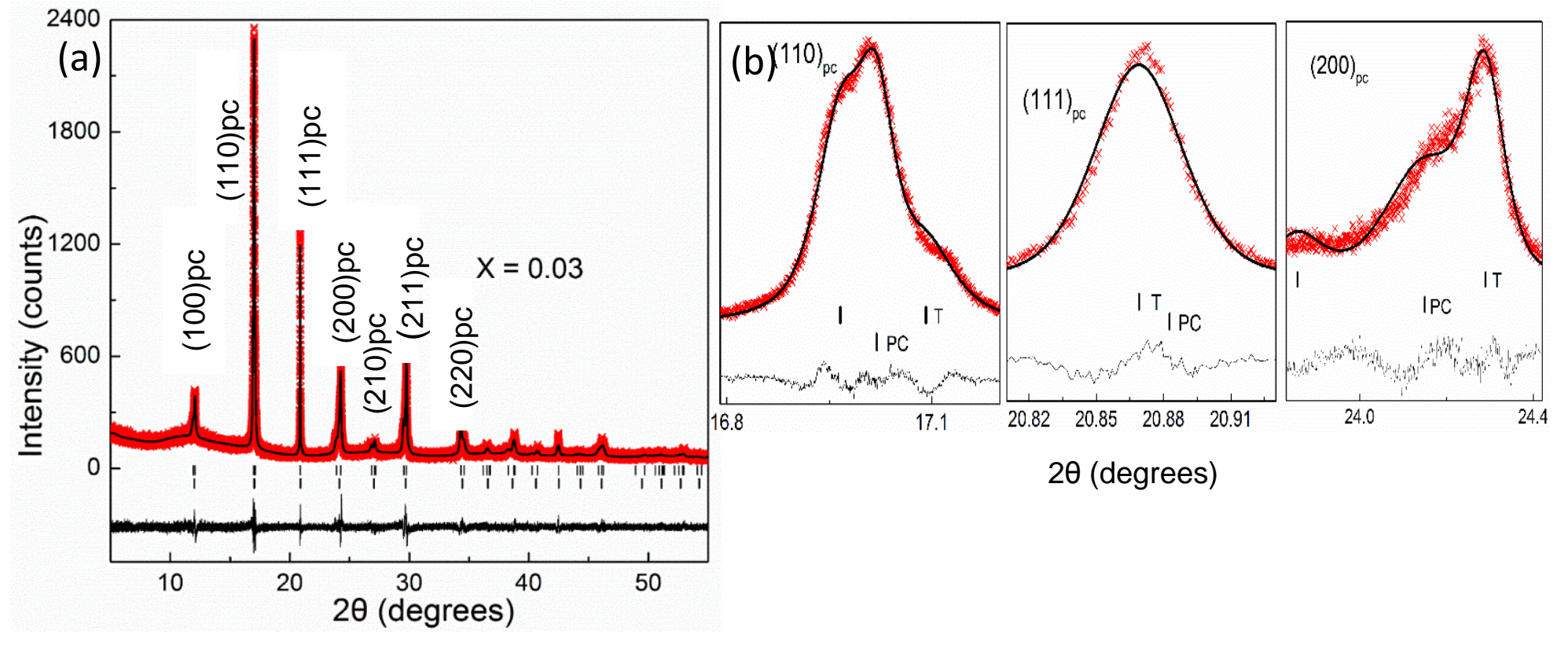



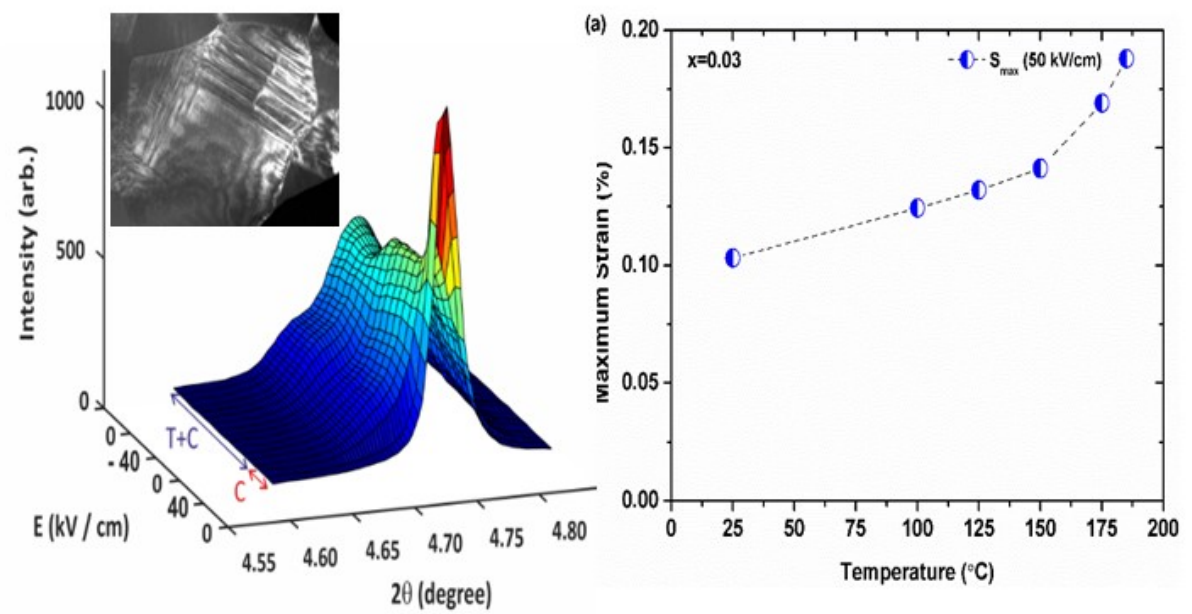